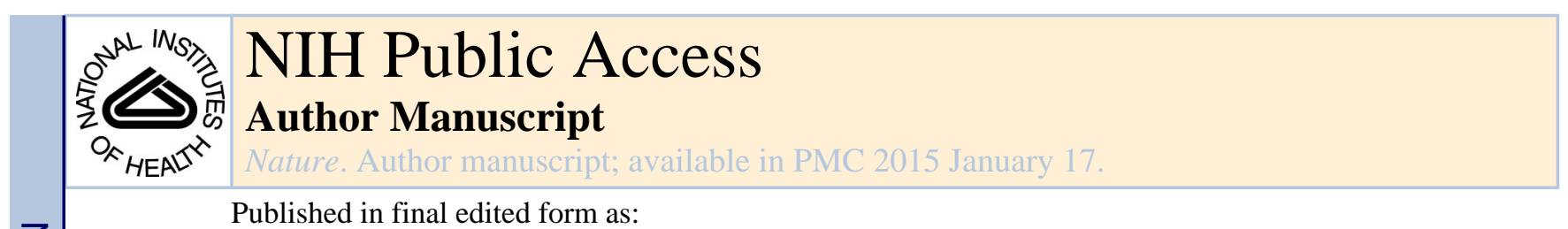

Published in final edited form as:

Nature. 2015 January 15; 517(7534): 386-390. doi:10.1038/nature13848.

\title{
CEACAM1 regulates TIM-3-mediated tolerance and exhaustion
}

\author{
Yu-Hwa Huang ${ }^{1}$, Chen Zhu ${ }^{2,{ }^{*}}$, Yasuyuki Kondo ${ }^{1,{ }^{*}}$, Ana C. Anderson ${ }^{2}$, Amit Gandhi ${ }^{1}$, \\ Andrew Russell ${ }^{3}$, Stephanie K. Dougan ${ }^{4}$, Britt-Sabina Petersen ${ }^{5}$, Espen Melum ${ }^{1,6}$, Thomas \\ Pertel $^{2}$, Kiera L. Clayton ${ }^{7}$, Monika Raab ${ }^{8}$, Qiang Chen ${ }^{9}$, Nicole Beauchemin ${ }^{10}$, Paul J. \\ Yazaki $^{11}$, Michal Pyzik ${ }^{1}$, Mario A. Ostrowski ${ }^{7,12}$, Jonathan N. Glickman ${ }^{13}$, Christopher E. \\ Rudd $^{8}$, Hidde L. Ploegh ${ }^{4}$, Andre Franke ${ }^{5}$, Gregory A. Petsko ${ }^{3}$, Vijay K. Kuchroo ${ }^{2}$, and \\ Richard S. Blumberg ${ }^{1}$ \\ ${ }^{1}$ Division of Gastroenterology, Department of Medicine, Brigham and Women's Hospital, Harvard \\ Medical School, 75 Francis Street, Boston, Massachusetts 02115, USA. \\ ${ }^{2}$ Evergrande Center for Immunologic Diseases, Harvard Medical School and Brigham and \\ Women's Hospital, Harvard Institutes of Medicine, 77 Avenue Louis Pasteur, Boston, \\ Massachusetts 02115, USA. \\ ${ }^{3}$ Rosenstiel Basic Medical Sciences Research Center, Brandeis University, 415 South Street, \\ Waltham, Massachusetts 02454, USA. \\ ${ }^{4}$ Whitehead Institute, Massachusetts Institute of Technology, Cambridge, Massachusetts 02142 , \\ USA.
}

${ }^{5}$ Institute of Clinical Molecular Biology, Christian-Albrechts-University of Kiel, Kiel 24105, Germany.

${ }^{6}$ Norwegian PSC Research Center, Division of Cancer Medicine, Surgery and Transplantation, Oslo University Hospital, Oslo 0424, Norway.

${ }^{7}$ Department of Immunology, University of Toronto, Toronto, Ontario M5S1A8, Canada.

${ }^{8}$ Cell Signalling Section, Department of Pathology, University of Cambridge, Cambridge CB2 1QP, UK.

${ }^{9}$ State Key Laboratory of Biotherapy, West China Hospital, Sichuan University, Chengdu 610041, China.

${ }^{10}$ Goodman Cancer Research Centre, McGill University, Montreal H3G 1Y6, Canada.

\footnotetext{
Correspondence and requests for materials should be addressed to R.S.B. (rblumberg@partners.org).

These authors contributed equally to this work.

Supplementary Information is available in the online version of the paper.

Author Contributions Y.-H.H., CZ. and Y.K. performed most experiments and helped prepare the manuscript. B.-S.P., E.M. and A.F. provided expertise in the genetic assessment for TIM-3. J.N.G. assessed all pathology. A.CA designed and directed tumour experiments. T.P. designed shRNA experiments. M.R and C.E.R. performed proximity ligation analysis. S.K.D. and H.L.P. conducted and analysed pulse-chase biosynthetic labelling experiments. A.G., A.R., Q.C. and G.A.P. performed X-ray crystallography or structural analysis. K.L.C. and M.A.O. conducted immune synapse experiments. M.P. and P.J.Y. assisted with the single chain protein analysis. N.B. assisted in generation of CeaCAM1 ${ }^{-/-}$Rag $2^{-/-}$mice and in analyses of data. R.S.B. and V.K.K. devised and coordinated the project, and together with Y.-H.H., C.Z. and Y.K. wrote the manuscript and designed the experiments. R.S.B. and V.K.K. share senior authorship on this paper.

The authors declare competing financial interests: details are available in the online version of the paper.
} 
${ }^{11}$ Beckman Institute, City of Hope, Duarte, California 91010, USA.

${ }^{12}$ Keenan Research Centre of St.Michael's Hospital, Toronto, Ontario M5S1A8, Canada.

${ }^{13}$ GI Pathology, Miraca Life Sciences, Newton, Massachusetts 02464, USA.

\section{Abstract}

T-cell immunoglobulin domain and mucin domain-3 (TIM-3, also known as HAVCR2) is an activation-induced inhibitory molecule involved in tolerance and shown to induce T-cell exhaustion in chronic viral infection and cancers ${ }^{1-5}$. Under some conditions, TIM-3 expression has also been shown to be stimulatory. Considering that TIM-3, like cytotoxic T lymphocyte antigen 4 (CTLA-4) and programmed death 1 (PD-1), is being targeted for cancer immunotherapy, it is important to identify the circumstances under which TIM-3 can inhibit and activate T-cell responses. Here we show that TIM-3 is co-expressed and forms a heterodimer with carcinoembryonic antigen cell adhesion molecule 1 (CEACAM1), another well-known molecule expressed on activated $\mathrm{T}$ cells and involved in T-cell inhibition ${ }^{6-10}$. Biochemical, biophysical and $\mathrm{X}$-ray crystallography studies show that the membrane-distal immunoglobulin-variable ( $\operatorname{IgV})$-like amino-terminal domain of each is crucial to these interactions. The presence of CEACAM1 endows TIM-3 with inhibitory function. CEACAM1 facilitates the maturation and cell surface expression of TIM-3 by forming a heterodimeric interaction in $\mathrm{cis}$ through the highly related membrane-distal N-terminal domains of each molecule. CEACAM1 and TIM-3 also bind in trans through their N-terminal domains. Both cis and trans interactions between CEACAM1 and TIM-3 determine the tolerance-inducing function of TIM-3. In a mouse adoptive transfer colitis model, CEACAM1-deficient $\mathrm{T}$ cells are hyper-inflammatory with reduced cell surface expression of TIM-3 and regulatory cytokines, and this is restored by T-cell-specific CEACAM1 expression. During chronic viral infection and in a tumour environment, CEACAM1 and TIM-3 mark exhausted T cells. Co-blockade of CEACAM1 and TIM-3 leads to enhancement of anti-tumour immune responses with improved elimination of tumours in mouse colorectal cancer models. Thus, CEACAM1 serves as a heterophilic ligand for TIM-3 that is required for its ability to mediate T-cell inhibition, and this interaction has a crucial role in regulating autoimmunity and anti-tumour immunity.

We examined the role of CEACAM1 in ovalbumin (OVA)-specific peripheral T-cell tolerance ${ }^{11}$. OVA protein administration (Extended Data Fig. 1a) resulted intolerance induction in wild-type OVA-specific T-cell receptor transgenic OT-II Rag $2^{-/-}$mice (Fig. 1a), but not in transgenic OT-II Ceacam $1^{-/-} \mathrm{Rag}^{-/-}$mice (Fig. 1b). Transfer of carboxyfluorescein diacetate succinimidyl ester (CFSE)-labelled naive $\mathrm{CD}^{+} \mathrm{Va}^{+} \mathrm{T}$ cells from transgenic OT-II Rag2 ${ }^{-/-}$mice into Ceacam $1^{-/}$recipients (Extended Data Fig. 1b, c) was associated with increased OVA induced proliferation (Fig. 1c) and TIM-3 expression uniformly restricted to proliferating CEACAM1 ${ }^{+} \mathrm{T}$ cells (Fig. 1d and Extended Data Fig. 1d).

$\mathrm{CD}^{+}{ }^{+} \mathrm{T}$-cell receptor (TCR) $\mathrm{V} \beta 8^{+} \mathrm{T}$ cells in $\mathrm{Ceacaml}^{-/-}$, but not wild-type, mice lacked TIM-3 expression after Staphylococcus aureus enterotoxin B (SEB) administration, suggesting CEACAM1 and TIM-3 co-expression on tolerized T cells (Extended Data Fig. 1e, f). Flag-tagged human (h) CEACAM1 enhanced cell surface expression of co-transfected 
haemagglutinin (HA)-tagged hTIM-3 in human embryonic kidney 293T (HEK293T) cells, with virtually all hTIM-3-positive HEK293T cells notably CEACAM1-positive (Fig. 1e). Human T cells co-expressed TIM-3 and CEACAM1 after in vitro activation with decreased CEACAM1 expression after TIM3 (also known as HAVCR2) silencing (Fig. 1f and Extended Data Fig. 1g, h). Human immunodeficiency virus (HIV)-infected, but not uninfected, subjects exhibited increased CEACAM1 ${ }^{+} \mathrm{TIM}^{+} 3^{+}$(double-positive) $\mathrm{CD} 4^{+} \mathrm{T}$ cells, which were poor producers of interferon- $\gamma(\mathrm{IFN}-\gamma)$, as were double-positive $\mathrm{CD} 8^{+} \mathrm{T}$ cells (Fig. 1g, h and Extended Data Fig. 1i-l). In situ proximity ligation analysis ${ }^{12}$ of hCEACAM1 and hTIM-3 co-transfected HEK293T cells (Fig. 1i and Extended Data Fig. $1 \mathrm{~m}-\mathrm{o}$ ), and co-cultures of activated primary human T cells (Extended Data Fig. 1p, q) confirmed the nearness of both molecules on the cell surface of HEK293T cells and colocalization within the immune synapse of activated $\mathrm{T}$ cells, respectively.

TIM-3 has been proposed to engage an unknown ligand ${ }^{13}$ (Extended Data Fig. 2a-c), and we considered CEACAM1 a possible candidate that is known to homodimerize ${ }^{14}$. Modelling available X-ray crystallographic structures of mouse (m) CEACAM1 (ref. 14) and mTIM-3 (ref. 13) membrane-distal IgV-like, N-terminal domains predicted structural similarity with extensive interactions along their $\mathrm{FG}-\mathrm{CC}^{\prime}$ interface in cis and trans configurations (Extended Data Fig. 2d-g and Supplementary Information). Mouse T-cell lymphoma cells predicted to possess a novel TIM-3 ligand expressed CEACAM1 (refs 13, 15) (Extended Data Fig. 2h, i). hCEACAM1, but not integrin a5 (ITGA5) (Extended Data Fig. 3a), was co-immunoprecipitated with hTIM-3 and vice-versa from co-transfected HEK293T cells (Fig. 2a, b). Co-immunoprecipitation of CEACAM1 and TIM-3 was confirmed with activated primary human T cells (Extended Data Fig. 3b) and primary

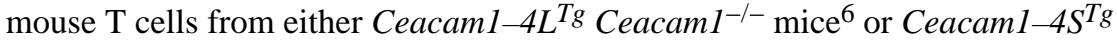
Ceacam $^{-/-}$mice $^{10}$ (transgenic mice in which CEACAM1 isoforms containing a long (L) or short (S) cytoplasmic tail, respectively, are conditionally overexpressed in T cells) ${ }^{7}$ (Extended Data Fig. 3c).

Although tunicamycin treatment had no effect (Extended Data Fig. 3d), mutation of amino acid residues including natural human allelic variants anticipated to be involved in these interactions disrupted the co-immunoprecipitation of hCEACAM1 and hTIM-3 in cotransfected HEK293T cells (Fig. 2c, d, Extended Data Fig. 3e-s, Extended Data Table 1 and Supplementary Information).

A single-chain of the hCEACAM1 N-terminal domain (amino acids 1-107) joined to the hTIM-3 N-terminal domain (amino acids 1-105) by a linker (GGGGS) 4 with a hexahistidine tag appended to the carboxy terminus was expressed in Escherichia coli (Extended Data Fig. 4a), and shown to interact specifically with the N-terminal domain of hTIM-3 by surface plasmon resonance (Extended Data Fig. 4b-e). This single-chain protein was crystallized and a structural model built from X-ray diffraction data (Extended Data Table 2). This revealed two similar copies of a hCEACAM1 (IgV domain)-hTIM-3 ( $\operatorname{IgV}$ domain) heterodimer interacting along each of the respective FG-CC' faces (Fig. 2e) and at amino acid contact points demonstrated to be involved in biochemical interactions between hCEACAM1 and hTIM-3 (Fig. 2f, g and Extended Data Fig. 4f-h), with no conformational changes of the hCEACAM1 IgV domain upon forming a heterodimer with hTIM-3 in 
comparison to a CEACAM1 homodimer (Extended Data Table 2, Extended Data Fig. 4i-k and Supplementary Information).

Metabolic labelling (Fig. 2h-j) showed overall enhancement of hTIM-3 biosynthesis after hCEACAM1 co-expression with decreased cell surface display, intracellular accumulation and hypoglycosylation of hTIM-3 when mutant, hypomorphic forms of hTIM-3 or hCEACAM1 were co-expressed in HEK293T cells (Extended Data Fig. 5a-e). Especially profound was a natural hTIM-3 variant (rs147827860 (Thr101Ile)) that although exhibiting normal core protein association with hCEACAM1 (Extended Data Fig. 5f) could not be rescued by hCEACAM1 co-expression and remained hypoglycosylated with increased intracellular retention and a near absence of cell surface expression (Fig. 2h, i, Extended Data Fig. 5a, b, e and Supplementary Information).

$\mathrm{CD} 4^{+} \mathrm{T}$ cells from SEB-treated Ceacam1 ${ }^{-1-}$ miceormice with transgenic overexpression of Tim3 (also known as Havcr2) in T cells ${ }^{16}$ lacking CEACAM1 expression $\left(\mathrm{Tim} 3^{\mathrm{Tg}}\right.$ Ceacam $1^{-1-}$ ) exhibited diminished expression of all mTIM-3 forms (fully glycosylated, hypoglycosylated and core protein) (Fig. 2k), decreased upregulation of TIM-3 expression on the cell surface (Fig. 2l) and blunted deletion of $\mathrm{CD} 4^{+} \mathrm{V} \beta 8^{+} \mathrm{T}$ cells (Extended Data Fig. $5 \mathrm{~g}$ ) relative to wild-type or transgenic $\operatorname{Tim} 3^{T g}$ mice expressing endogenous CEACAM1. Thelper $1\left(\mathrm{~T}_{\mathrm{H}} 1\right)$ polarized cells from $\operatorname{Tim}^{\mathrm{Tg}} \mathrm{Ceacam}^{--}$mice were resistant to galectin-9induced apoptosis (Extended Data Fig. 5h), which is dependent on TIM-3 expression as a glycoprotein ${ }^{15}$.

The hTIM-3 N-terminal domain bound hCEACAM1 and stained the cell surface of human CEACAM1-4L-transfected Jurkat T cells (Fig. 2m and Extended Data Fig. 5i, j). Transligation of wild-type mouse $\mathrm{CD}^{+}{ }^{+} \mathrm{T}$ cells with a mCEACAM1 $\mathrm{N}$-terminal domain-Fc fusion protein $(\mathrm{NFc})$ rendered them unresponsive to in vitro stimulation with anti-CD3 and anti-CD28 (Fig. 2n and Extended Data Fig. 5k). CD4 ${ }^{+}$T cells from SEB-treated Tim3 $3^{T g}$ or Tim3 Ceacaml $^{-1-}$ mice exhibited similar levels of TIM-3 associated BAT3, a repressor of TIM-3 cytoplasmic tail signalling ${ }^{17}$, at the time of T-cell isolation (Fig. 2o). However, only T cells from SEB-tolerized Tim $^{\text {Tg }}$ mice, but not SEB-treated Tim $3^{\text {Tg }}$ Ceacam $^{-1-}$ mice that were resistant to SEB-induced tolerance, exhibited BAT3 dissociation from mTIM-3 after $\mathrm{NFc}$ fusion protein ligation with further release observed after addition of anti-CD3 (Fig. 2o and Extended Data Fig. 51, m). We observed similar levels of NFc fusion protein staining of primary T cells from $\operatorname{Tim}^{\mathrm{Tg}}$ and $\mathrm{Tim}^{\mathrm{Tg}} \mathrm{Ceacam}^{-/-}$mice, relative to that observed with Ceacam $1^{-1-}$ mice, which was blocked by a TIM-3-specific antibody (Extended Data Fig. $5 \mathrm{n}$ ), implicating heterophilic ligation of TIM-3 as the major factor responsible for T-cell inhibition and BAT3 release.

Highly activated $\mathrm{CD} 4^{+} \mathrm{T}$ cells from wild-type and $\mathrm{Ceacam}^{-/-}$mice were transduced with a retrovirus encoding green fluorescent protein (GFP) plus mTIM-3. Anti-CD3 induced proliferation and TNF-a secretion was inhibited by NFc fusion protein ligation in transduced wild-type but not $\mathrm{Ceacam}^{-/-} \mathrm{T}$ cells or all groups transduced with GFP alone (Fig. 2p, q and Extended Data Fig. 5o, p). Both wild-type and Ceacam $1^{-/-}$T-cell transductants with a mTIM-3 cytoplasmic tail deletion construct (TIM-3 $\left.{ }^{\Delta 252-281}\right)^{17,18}$ were 
unresponsive to anti-CD3 stimulation or NFc fusion protein ligation (Fig. 2p, q and Extended Data Fig. 5o, p).

Tolerance pathways are important in T-cell regulation ${ }^{19}$. We detected homozygous rs147827860 (Thr101Ile) carriage in inflammatory bowel disease (IBD) but not controls (Extended Data Table $3 \mathrm{a}-\mathrm{c}$ ). We thus transferred naive $\mathrm{CD} 4^{+} \mathrm{CD} 62 \mathrm{~L}^{\text {high }} \mathrm{CD} 44^{-} \mathrm{T}$ cells from wild-type mice into Ceacaml ${ }^{-/} \mathrm{Rag}^{-{ }^{--}}$recipients and observed colon-infiltrating CEACAM $1^{+}$TIM $-3^{+}$T cells expressing markedly decreased intracellular levels of IFN- $\gamma$, IL-2 and IL-17A relative to other lamina propria T cells (Fig. 3a, b). Colon-infiltrating lamina propria $\mathrm{T}$ cells from adoptive transfer of naive $\mathrm{Ceacam}^{-/-} \mathrm{CD} 4^{+} \mathrm{T}$ cells into Ceacaml ${ }^{-/-}$Rag2 $^{-/-}$recipients expressed reduced cell surface levels of TIM-3 (Fig. 3c) and increased intracellular levels of TNF-a (Fig. 3d) in association with a severe progressive colitis with increased mortality (Fig. 3e, dagger symbol), and histopathological evidence of injury (Fig. 3f) characterized by acute and chronic inflammation (Extended Data Fig. 6a). Reestablishment of T-cell-specific mCEACAM1-4L expression using CeaCAM1-4L $\mathrm{L}^{T g}$ CeaCAM1 ${ }^{-1-}$ mice $^{6}$, restored TIM-3 display and decreased intracellular TNF-a expression by the infiltrating lamina propria $\mathrm{T}$ cells together with decreased disease severity (Fig. 3c-f and Extended Data Fig. 6b), reflective of CEACAM1 ${ }^{+}$TIM- $3^{+}$T-cell restoration.

$\mathrm{CD}^{+}{ }^{\mathrm{T}}$ cells from $\mathrm{Tim}^{\mathrm{Tg}} \mathrm{CeaCAM1^{-/- }}$ mice, in contrast to those from CEACAM1proficient $\mathrm{Tim} 3^{\mathrm{Tg}}$ mice, were hyper-inflammatory after transfer into $\mathrm{CeaCAM1^{-/- }} \mathrm{Rag} 2^{-/-}$ recipients and caused significant weight loss and severe colitis with increased expression of $\mathrm{T}_{\mathrm{H}} 17$ signature genes (Fig. 3g-i and Extended Data Fig. 6c, d). Nanostring (Extended Data Fig. 6e) and quantitative PCR (Fig. 3j) analysis of lamina propria mononuclear cells demonstrated increased transcripts for Ebi3, IL-27p28 (also known as Il27) and $I L-12 p 35$ (also known as Il12a) encoding the regulatory cytokines IL-27 and IL-35 (refs 20, 21) in CeaCAM1 ${ }^{-/-} \mathrm{Rag}^{-/-}$recipients of $\mathrm{CD} 4^{+} \mathrm{T}$ cells from $\operatorname{Tim}^{\mathrm{Tg}}$ relative to wild-type mice, and their absence in recipients of $\mathrm{CeaCAM1^{-1- }}$ or Tim ${ }^{\text {Tg }} \mathrm{CeaCAM1}^{-1-} \mathrm{T}$ cells.

Anti-tumour immunity is hindered by T-cell expression of inhibitory molecules associated with an exhausted phenotype ${ }^{22}$. We observed high levels of CEACAM $1^{+} \mathrm{TIM}^{-} 3^{+}$, relative to $\mathrm{PD}-1^{+} \mathrm{TIM}-3^{+}, \mathrm{CD} 4^{+}$and $\mathrm{CD} 8^{+} \mathrm{T}$ cells at the tumour site of wild-type mice in the azoxymethane (AOM)/dextran sodium sulphate (DSS) model of colitis-associated colon cancer (Extended Data Fig. 6f-j). At 2.5\% DSS, Tim $3^{T g}$ mice exhibited $100 \%$ fatality, significantly greater than all other genotypes (Fig. 4a). Tumour quantification at a lower DSS dose (1.5\%) showed that the polyp numbers, polyp size, high-grade dysplasia and frank carcinoma were significantly higher in $\operatorname{Tim} 3^{T g}$ than in wild-type mice with decreased neoplasia observed in $\mathrm{Tim}^{\mathrm{Tg}} \mathrm{CeaCAM1^{-/- }}$ and $\mathrm{CeaCAM1^{-/- }}$ mice (Fig. $4 \mathrm{~b}-\mathrm{d}$ and Extended Data Fig. 6k).

After implantation of colorectal cancer cells (CT26) subcutaneously in BALB/c mice, a significant fraction of $\mathrm{CD} 8^{+}$tumour infiltrating lymphocytes (TILs) was triple-positive $\mathrm{T}$ cells $\left(\mathrm{TIM}-3^{+} \mathrm{PD}-1^{+} \mathrm{CEACAM} 1^{+}\right.$), with the relative cell surface levels of TIM-3 correlating with CEACAM1 (Fig. 4e). PD-1 ${ }^{+}$TIM- $3^{\text {bright }}$ CEACAM1 ${ }^{+}$T cells were characterized by extremely low intracellular IL-2 and TNF-a expression consistent with exhaustion (Fig. 4f). Co-administration of an anti-mCEACAM1 and anti-mTIM-3 antibody delayed subcutaneous 
tumour growth in a preventative model (Fig. 4g and Extended Data Fig. 7a), and was able to exceed protection with co-blockade of PD-1 and TIM-3 (Extended Data Fig. 7b, c). In a therapeutic model, blockade of CEACAM1 synergized with PD-1 inhibition (Extended Data Fig. 7d, e). CEACAM1 and TIM-3 co-blockade was associated with increased CD8 ${ }^{+}$(Fig. 4h) and $\mathrm{CD}^{+}$(Fig. 4i) TILs with enhanced IFN- $\gamma$ production (Fig. 4j) and decreased IL-10 production (Extended Data Fig. 7f) by the infiltrating $\mathrm{CD} 8^{+}$and $\mathrm{CD} 4^{+} \mathrm{T}$ cells, respectively. Increased tumour antigen-specific $\mathrm{CD} 8^{+} \mathrm{T}$ cells defined by AH1-tetramer staining ${ }^{23}$, relative to the total $\mathrm{CD} 8^{+}$T-cell population (Fig. 4k and Extended Data Fig. 7g) was observed in the draining lymph nodes that correlated with tumour growth inhibition (Extended Data Fig. 7h). CT26 tumour growth was impeded in CeaCAM1-/- mice (Fig. 4l) in association with increased $\mathrm{AH}-1$ tetramer ${ }^{+} \mathrm{CD}^{+} \mathrm{T}$ cells in draining lymph nodes (Fig. $4 \mathrm{~m}$ and Extended Data Fig. 7i) and decreased TIM-3 expression on tumour-associated TILs (Fig. 4n).

In conclusion, we show that CEACAM1 and TIM-3 form a new heterodimeric complex that is determined by interactions between their structurally similar membrane-distal IgV-like, $\mathrm{N}$-terminal domains. This association is evident during early biosynthesis and crucial for proper maturation, cell surface display and function of TIM-3 and probably CEACAM1 when expressed together. CEACAM1 also functions as an essential trans-heterophilic ligand for TIM-3 with the tolerance-inducing functions of TIM-3 requiring interactions with CEACAM1 in both cis and trans configurations. CEACAM1 expression with TIM-3 is further characteristic of $\mathrm{T}$ cells with an exhausted phenotype such that in the absence of these interactions inflammatory responses are unrestrained and anti-tumour immunity enhanced. Together, these studies describe a novel class of heterodimeric protein interactions that function in tolerance induction with broad implications for many types of infectious, autoimmune and neoplastic conditions.

Online Content Methods, along with any additional Extended Data display items and Source Data, are available in the online version of the paper; references unique to these sections appear only in the online paper.

\section{METHODS}

\section{Mice}

C57BL/6 and BALB/c mice were purchased from Jackson Laboratory. Ceacam ${ }^{-/-}$mice (C57BL/6 and BALB/c backcrosses) were generated by N. Beauchemin ${ }^{24}$. Transgenic OT-II Ceacaml ${ }^{-1-} \mathrm{Rag}^{-/-}$mice were generated by first crossing Ceacam ${ }^{-1-}$ mice to

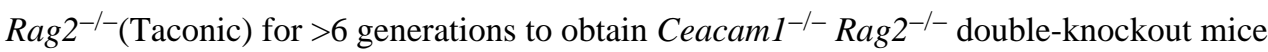
on aC57BL/6 background, followed by crossing these mice to transgenic OT-II Rag $2^{-/-}$ mice (Taconic) for $>9$ generations.Tim ${ }^{T g}$ (ref. 16) and Ceacam1 ${ }^{-1-}$ mice on a C57BL/6 background were intercrossed to generate $\operatorname{Tim}^{T g} \mathrm{Ceacam1}^{-1-}$ mice. Ceacam1-4L ${ }^{\mathrm{Tg}}$ Ceacam $^{-1-}$ and Ceacam $1-4 S^{T g}$ Ceacam $^{--}$mice have been previously described ${ }^{6,10}$. All studies were performed in mice with a C57BL/6 genetic background except for CT26 tumour experiments that were in a BALB/c genetic background. Animal studies were conducted in a gender and age-matched manner for all experiments. Both male and female mice were used and were 6-8 weeks of age at the time of experiments or 6-10 weeks for the 
adoptive transfer colitis experiments. The number of animals used per group was based on previous experimental results and observed variability. Histopathology analysis was performed in a blinded manner by an expert pathologist (J.N.G.). For all other in vitro and in vivo analyses, investigators were not blinded to treatment allocation. All experiments were approved and conducted according to the guidelines set forth by the Harvard Medical Area Standing Committee on Animals.

\section{Genotyping}

Mouse tails were digested in tail lysis buffer (100 mM Tris-HCl, $\mathrm{pH}$ 8.5, 5 mM EDTA, $0.2 \% \mathrm{SDS}, 200 \mathrm{mM} \mathrm{NaCl}$ and proteinase $\mathrm{K}$ (Roche)) overnight at $55^{\circ} \mathrm{C}$. Genomic DNA was phenol-extracted and isopropanol precipitated. DNA was dissolved in TE buffer. The primer sequences for genotyping are available on request.

\section{T-cell tolerance animal models}

For SEB tolerance induction model, animals of the indicated genotypes were injected intraperitoneally with $25 \mu \mathrm{g}$ of SEB (Millipore) on days 0 and 4, and euthanized at day 8 after the first injection. Peripheral lymph node cells were isolated and stained for T-cell receptor V $\beta 6, \mathrm{~V} \beta 8$ and CD4, and analysed for TIM-3 and CEACAM1 expression on CD4 ${ }^{+}$ $\mathrm{V} \beta 8^{+}$cells. Cells were also re-stimulated in vitro at $0.5 \times 10^{6}$ cells per ml with anti-CD3 $\left(0.1-10.0 \mu \mathrm{g} \mathrm{ml}^{-1}\right)$ and assessed for proliferation by $\left[{ }^{3} \mathrm{H}\right]$-thymidine $\left(1 \mu \mathrm{Ci} \mathrm{m}^{-1}\right)$ uptake or production of IL-2 by ELISA. For OVA antigen-specific T-cell tolerance induction, highdose OVA antigen was used and modified according to previous studies ${ }^{11,25,26}$. In brief, transgenic OT-II Rag $2^{-/-}$or Ceacam $1^{-/-} \mathrm{Rag}^{-/-}$mice were injected intraperitonally with $500 \mu \mathrm{g}$ of OVA peptide (323-339, 323-ISQAVHAAHAEINEAGR-329, AnaSpec) in an equal volume a mount of complete Freund's adjuvant (CFA) or PBS alone at day 0 (activation of immune response) and at day 4 (tolerance induction). At day $10, \mathrm{CD}^{+} \mathrm{T}$ cells were isolated from spleens and pooled peripheral lymphocytes from each experimentally treated mouse as indicated above. The pooled lymphocytes from each mouse were restimulated in vitro with various concentrations of $\operatorname{OVA}_{323-339}$ peptide $(0.1,1,2.5$ and $10 \mu \mathrm{g}$ $\mathrm{ml}^{-1}$ ). The 96-well cultures were set up with a total cell number of $2.5 \times 10^{4}$ in $200 \mu \mathrm{RPMI}$ complete medium pulsed with $1 \mu \mathrm{Ci}\left[{ }^{3} \mathrm{H}\right]$-thymidine (PerkinElmer Life Sciences) for the final $8 \mathrm{~h}$ of the $72 \mathrm{~h}$ assay, and collected with a Packard Micromate cell harvester. Counts per minute (c.p.m.) were determined using a Packard Matrix 96 direct counter (Packard Biosciences) and data expressed as median values. For in vivo tracking of OVA-specific antigen-specific T-cell responses, adoptive transfer experiments were performed on the basis of previous studies ${ }^{27}$. In brief, $\mathrm{CD} 4^{+} \mathrm{Va}^{+} \mathrm{T}$ cells were isolated from spleens and pooled peripheral lymphocytes of transgenic OT-II Ceacaml ${ }^{+/+}$(wild-type) Rag $^{-/-}$mice and the cells were pre-incubated for 10 min with $4 \mathrm{mM}$ CFSE in PBS plus $0.1 \%$ FBS. CFSElabelled cells $\left(5 \times 10^{5}\right)$ were injected intravenously by tail vein into syngeneic C57BL/6 wild-type or Ceacam $1^{-1-}$ recipients. After $18 \mathrm{~h}$ to allow the adoptively transferred $\mathrm{T}$ cells to establish themselves in vivo, and which showed no differences in parking of the $\mathrm{T}$ cells among the various genotypes, the mice were then immunized with $\mathrm{OVA}_{323-339}(50 \mu \mathrm{g})$ in an equal volume of CFA. On day 3, cells were collected from spleen, mesenteric lymph and peripheral lymph node of individual mice and stained with DAPI to exclude dead cells, and concurrently stained with anti-CD4-PerCp, anti-CEACAM1- allophycocyanin and anti- 
TIM-3-phycoerythrin. Total lymphocytes were gated and the CFSE subset representing the transgenic OT-II, adoptively transferred $\mathrm{CD} 4^{+} \mathrm{T}$ cells analysed and CEACAM1- and TIM-3-expression assessed on the CFSE-positive cells.

\section{Cell lines}

3T3 mouse fibroblast cells, the TK-1 mouse T cell lymphoma cell line, the HEK293T cell line, and CT26 mouse colorectal cancer cell lines were all purchased from ATCC as mycoplasma-free cell lines and culture conditions were all followed according to ATCC instructions. Human CEACAM1-4L transfected human Jurkat T-cell line and human CEACAM1-4L transfected HeLa cells have been previously described (provided by J. Shively and S. G. Owen) $)^{28,29}$.

\section{Antibodies and reagents}

An anti-CEACAM1 monoclonal antibody that binds to the $\mathrm{C}-\mathrm{C}^{\prime}$ loop of mCEACAM1 (ref. 30) (cc1, provided by K.V. Holmes and J. Shively) and isotype control (mouse IgG1) antibodies for the in vivo injection experiments were purchased from Bio X Cell. An Fc fusion protein consisting of the N-terminal domain of mouse CEACAM1 together with human IgG1, N-CEACAM1-Fc ${ }^{31}$ was provided by T. Gallagher. The following fluorochrome-conjugated antibodies were purchased from BioLegend: anti-IFN- $\gamma$ (XMG1.2), anti-IL-2 (JES6-5H4), anti-IL-17A (TC11-18H10.1), anti-IL-10 (JES5-16E3) and PD-L1 (10F.9G2); and other antibodies were purchased from eBioscience: anti-CD3 (clone, 145-2C11), anti-CD28 (clone 37.51), anti-CD8a (clone, 53-6.7), anti-CD4 (clone, RM4-5), anti-TNF-a (clone, MP6-XT22) and anti-TIM-3 (clone, 8B.2C12). The BAT3 antibody (clone AB10517) was purchased from Millipore. Brefeldin A and monensin were from eBioscience. The anti-TIM-3 5D12, 2C12, 2E2, 2E12 and 3F9 antibodies were generated in V.K.K.'s laboratory and 5D12 was conjugated to phycoerythrin and allophycocyanin by BioLegend. The anti-human CEACAM1 antibodies specific for the Nterminal domain (34B1, 26H7 and 5F4) have been previously described and characterized in R.S.B.'s laboratory ${ }^{32,33}$. All the antibodies used for biochemical experiments if otherwise indicated, were purchased from Cell Signaling. Tunicamycin was purchased from Sigma.

\section{Primary human T-cell isolation}

Human peripheral blood mononuclear cells (PBMCs) were isolated from buffy coats from healthy anonymous donors according to an Institutional Review Board approved protocol from Brigham and Women's Hospital. $\mathrm{CD}^{+} \mathrm{T}$ cells were purified from PBMC using CD4 Microbeads (Miltenyi) and cultured in RPMI-1640 supplemented with 10\% FBS (Invitrogen), L-glutamine, non-essential amino acids, sodium pyruvate, $20 \mathrm{mM}$ HEPES and $100 \mathrm{IU} \mathrm{ml}^{-1}$ recombinant human IL-2 (R\&D Systems). The T cells were stimulated with plate-bound anti-CD3 (OKT3) and anti-CD28 (CD28.2) antibodies $\left(1 \mu \mathrm{g} \mathrm{ml}^{-1}\right.$ each, eBioscience).

\section{Cellular based studies on HIV-infected individuals}

In the analysis of HIV-infected individuals, informed consent was obtained in accordance with the guidelines for conduction of clinical research at the University of Toronto and 
Maple Leaf Clinic institutional ethics boards. Written informed consent was provided for this study, which was reviewed by research ethics board of the University of Toronto, Canada and of St. Michael's Hospital, Toronto, Canada. Individuals were recruited from a Toronto-based cohort (Maple Leaf Clinic and St. Michael's Hospital, Toronto, Canada). Samples were obtained from HIV-positive chronically infected antiretroviral treatment naive individuals (infected $>1$ year, with detectable viral load) and demographically matched HIVseronegative individuals. Whole blood was collected in anti-coagulant treated tubes and PBMCs were isolated using Ficoll-Paque PLUS (GE Healthcare Bio-Sciences) and stored at $-15{ }^{\circ} \mathrm{Cuntil}$ future use. PBMCs from healthy HIV-1-uninfected and HIV-1-infected individuals were stained with CEACAM1 monoclonal antibody (clone 26H7), detected with a fluorophore-conjugated secondary antibody, followed by fluorophore-conjugated monoclonal antibodies to CD4, CD8 and CD3 (BioLegend), and TIM-3 (R \& D Systems) to determine phenotype assessment. An Aqua amine dye (Invitrogen) was used to discriminate live and dead cells. For functional experiments, cells were stimulated after thawing with 1 $\mu \mathrm{g} \mathrm{ml}^{-1}$ of overlapping HIV-1 Clade B Gag peptide pool (National Institutes of Health AIDS Reagent Program), or $1 \mu \mathrm{g} \mathrm{ml}^{-1}$ SEB (Sigma Aldrich) in the presence of brefeldin A (Sigma) for $6 \mathrm{~h}$. Surface staining was followed by a fixation and per-meabilization step. Intracellular staining for cytokines was performed using anti-IFN- $\gamma$ (Biolegend). Cells were fixed in $2 \%$ formalin/PBS and acquired with a modified LSRII system (BD Biosciences). A total of 100,000 events were collected and analysed with FlowJo software (Tree Star).

\section{In situ proximity ligation assay}

Proximity ligation assay was performed using Duolink in situ PLA reagents on HEK293T cells co-transfected with human CEACAM1- Flag-tagged and human TIM-3-HA-tagged vectors. Primary antibodies used were anti-Flag or anti-HA antibodies and followed by secondary antibodies. Cells on slides were blocked with Duolink Blocking stock followed by the application of two PLA probes in $1 \times$ antibody diluent. The slides were washed in a wash buffer ( $1 \times$ TBS-T) for 5 min twice and processed for hybridization using Duolink Hybridization stock 1:5 in high purity water and followed by incubation for 15 min at $37^{\circ} \mathrm{C}$. Duolink Ligation was performed with ligase and the slides were incubated in a pre-heated humidity chamber for $15 \mathrm{~min}$ at $37^{\circ} \mathrm{C}$. Amplification was then achieved using Duolink Amplification stock containing the polymerase and the slides were incubated again in a preheated humidity chamber for $90 \mathrm{~min}$ at $37^{\circ} \mathrm{C}$. DNA was stained with DAPI. A proximity ligation assay probe generates a fluorescent signal only when it binds to two primary antibodies (anti-HA and anti-Flag) attached to two proteins that are in maximum distance of $30-40 \mathrm{~nm}$ (ref. 12) to each other. One individual dot represents the close proximity of two interacting proteins within the cells.

\section{Confocal microscopy of T-B-cell conjugates}

$\mathrm{CD}^{+}$and $\mathrm{CD} 8^{+} \mathrm{T}$ cells were isolated from human PBMCs by negative selection (EasySep, StemCell Technologies) and expanded by incubation with $1 \mu \mathrm{g} \mathrm{ml}^{-1}$ anti-CD3 (clone OKT3; BioLegend), $1 \mu \mathrm{g} \mathrm{ml}^{-1}$ anti-CD28 monoclonal antibody (clone 28.8; BioLegend) with $50 \mathrm{U}$ $\mathrm{ml}^{-1}$ of recombinant IL-2 (National Institutes of Health) in complete RPMI media for 5 days to upregulate CEACAM1 and TIM-3. After overnigh trest, T cells were mixed in a 2:1 ratio with Cell Tracker Blue CMAC (Invitrogen)-labelled human EBV-transformed B cells pre- 
loaded with SEB (Sigma-Aldrich), and brought into contact by centrifugation at $200 \mathrm{~g}$ for 5 min. Cells were incubated at $37{ }^{\circ} \mathrm{C}$ for $10 \mathrm{~min}$ and deposited onto poly-L-lysine coated coverslips for an additional $15 \mathrm{~min}$. Cells were fixed in $4 \%$ formaldehyde, permeabilized, blocked and stained with primary antibodies against CD3- $\varepsilon$ (Abcam), CEACAM1 (clone5F4) and TIM-3 (R\&D Systems) and appropriate fluorescently labelled secondary antibody. After immunofluorescent labelling, coverslips were mounted on glass slides using ProLong Gold antifade reagent (Invitrogen) and cured in the dark at room temperature for 24h. Imaging was performed on an Olympus IX81 confocal microscope. Z-stack images $(0.15 \mu \mathrm{m})$ of conjugates were acquired with a $\times 60$ Plan-Apochromat oil objective, numerical aperture 1.42 .

\section{Image processing and analysis}

All fluorescence images were background subtracted, annotated and exported using Olympus Fluoview FV100 image viewer. Colocalization analysis and Pearson's correlation coefficient was calculated from corresponding interface regions from two channels using Volocity. For presentation in figures, images were adjusted and cropped equally across related groups.

\section{Mutagenesis of human CEACAM1 and TIM-3}

Point mutations were introduced by PCR-based mutagenesis, using the QuikChange II SiteDirected Mutagenesis Kit (Agilent Technologies). The mutant oligonucleotides are listed in Extended Data Table 1a, b. Previously described vectors containing the human CEACAM1$3 \mathrm{~L}$ variant ${ }^{34}$ and human TIM-3 in the pDisplay vector (Invitrogen) ${ }^{35}$ were used as the template for all mutations. PCR reactions for single amino acid mutations were run for 16 cycles of 30s at $95{ }^{\circ} \mathrm{C}$ and $1 \mathrm{~min}$ at $55^{\circ} \mathrm{C}$, followed by 6 min at $68{ }^{\circ} \mathrm{C}$. The resulting mutant plasmids were verified by Sanger DNA sequencing. TIM-3 amino acid residues were numbered according to National Center for Biotechnology Information database.

\section{Cell culture, transfection, tunicamycin treatment, immunoprecipitation and immunoblotting}

HEK293T cells transfected with the 1,200 ng of Flag-tagged human CEACAM1 wild-type or mutant vectors or 1,200 ng of Flag-tagged ITGA5 (NM_002205; Origene) and 1,200 ng of HA-tagged human TIM-3 wild-type or mutant vectors or 1,200 $\mathrm{ng}$ of vector controls when mono-transfections were performed and cells transfected for $48 \mathrm{~h}$. In some experiments, $6 \mathrm{~h}$ after transfection, transfected cells were treated with $2 \mu \mathrm{g} \mathrm{m} l^{-1}$ or $10 \mu \mathrm{g}$ $\mathrm{ml}^{-1}$ tunicamyin provided in DMSO for the last $24 \mathrm{~h}$ of transfection. Transfected cells were washed once with cold PBS and lysed on ice with $0.5 \mathrm{ml}$ of immunoprecipitation buffer containing $20 \mathrm{mM}$ Tris- $\mathrm{HCl}, 0.15 \mathrm{M}$ sodium chloride, $\mathrm{pH} 7.6$, with protease inhibitor cocktail tablets (Roche) and 1.0\% digitonin (Sigma). After $60 \mathrm{~min}$, the cell lysates were spun at 14,000 r.p.m. for $30 \mathrm{~min}$ at $4{ }^{\circ} \mathrm{C}$. The lysate was subsequently incubated with $5 \mu \mathrm{l}$ of protein A-Sepharose (Sigma) that had been pre-adsorbed with an equal volume of immunoprecipitation buffer followed by three 1-h incubations with protein A-Sepharose. The pre-cleared lysates were incubated for $2 \mathrm{~h}$ at $4{ }^{\circ} \mathrm{C}$ with $10 \mu \mathrm{l}$ of protein A-Sepharose beads bound to the specific antibodies. Some immunoprecipitates were incubated with 
agarose-HA antibody. The control and specific immunoprecipitates were washed with immunoprecipitation buffer and re-suspended in $30 \mu \mathrm{l}$ of Laemmli sample buffer without reducing agents. After boiling for $5 \mathrm{~min}$, the proteins were resolved by SDS-PAGE in regular Tris-glycine buffer on a 4-20\% Tris-Glycine Gel (Novex). The proteins were electrically transferred to a PVDF (polyvinylidene difluoride) membrane. After blocking with 5\% skim milk in $0.05 \%$ PBS-Tween (PBS-T), the membranes were incubated for $12 \mathrm{~h}$ at $4{ }^{\circ} \mathrm{C}$ with primary antibodies. The membranes were further incubated with corresponding secondary antibodies for $1 \mathrm{~h}$ at room temperature and visualized by Amersham ECL Western Blotting Detection Reagents (GE Healthcare). The specific antibodies used for immunoprecipitation and immunoblotting in this assay were anti-Flag antibody produced in rabbit (Sigma), HA.11 (16B12) (Covance), anti-HA-Tag-agarose (MBL, Medical \& Biological Laboratories Co), anti-HA antibody produced in rabbit and in mouse (Sigma) and anti-human CEACAM1 antibody, 5F4. Unsaturated films were digitally scanned and band intensities (densitometric analysis) were quantified using ImageJ (NIH).

\section{Co-immunoprecipitation of primary $\mathrm{T}$ cells}

Primary human $\mathrm{CD}^{+} \mathrm{T}$ cells were purified and activated with plate bound anti-CD3 $(1 \mu \mathrm{g}$ $\left.\mathrm{ml}^{-1}\right)$ and anti-CD28 $\left(1 \mu \mathrm{g} \mathrm{ml}^{-1}\right)$ in the presence of recombinant (r) IL-2 $\left(10 \mathrm{ng} \mathrm{ml}^{-1}\right.$; NIH) for 5 days. Cells were then rested in rIL-2 containing $\left(10 \mathrm{ng} \mathrm{ml}^{-1}\right)$ complete medium for 3 days and re-stimulated with soluble anti-CD3 $\left(1 \mu \mathrm{g} \mathrm{ml}^{-1}\right)$ for 2 days. Cell lysates were prepared as above and treated with $N$-glycanase by the manufacturer's suggested protocol (Promega). $\mathrm{N}$-glycanase treated lysates were immunoprecipitated with anti-human TIM-3 antibodies (2E2, 2E12 and 3F9) or mouse IgG1 as control and the immunoprecipitates subjected to SDS-PAGE and transferred to PVDF membranes followed by immunoblotting with the mouse anti-human CEACAM1 monoclonal antibody, 5F4, as described above. Primary mouse splenocytes were prepared from Ceacam $1-4 L^{T g}$ Ceacaml ${ }^{-1-}$ and Ceacam1$4 S^{T g} \mathrm{Ceacaml}^{-/-}$mice and cultured in the presence of anti-CD3 $\left(1 \mu \mathrm{g} \mathrm{m}{ }^{-1}\right)$ or anti-CD3 (1 $\left.\mu \mathrm{g} / \mathrm{ml}^{-1}\right)$ plus anti-CD28 $\left(1 \mu \mathrm{g} \mathrm{ml}^{-1}\right)$ or medium only for $96 \mathrm{~h}$. Cell lysates were prepared, immunoprecipitated with cc1 (anti-mCEACAM1) and immunblotted with 5D12 (antimTIM-3) monoclonal antibodies as described above.

\section{Pulse-chase experiments, immunoprecipitation, endoglycosidaseH digestion and SDS- PAGE}

Cells were transfected as above with wild-type human HA-tagged hTIM-3 or Thr101Ile variant of HA-tagged hTIM-3 with or without co-transfection with Flag-tagged human CEACAM1 vector. All transfections included a co-transfection with Flag-tagged influenza virus M2 protein (M2) encoding vector as a non-binding control. After 48h, transfected HEK293T cells were incubated with methionine- and cysteine-free DMEM for $30 \mathrm{~min}$ at 37 ${ }^{\circ} \mathrm{C}$. Cells were labelled with $10 \mathrm{mCi} \mathrm{ml}^{-1}\left[{ }^{35} \mathrm{~S}\right]$-methionine/cysteine $\left(1,175 \mathrm{Ci} \mathrm{mmol}^{-1}\right.$; PerkinElmer Life Sciences) at $37^{\circ} \mathrm{C}$ for the indicated times and chased with DMEM at 37 ${ }^{\circ} \mathrm{C}$ for the indicated times. Cells were lysed in Nonidet P-40 lysis buffer $(50 \mathrm{mM}$ Tris, pH7.4, 0.5\% Nonidet P-40, $5 \mathrm{mM} \mathrm{MgCl}_{2}$, and $150 \mathrm{mM} \mathrm{NaCl}$ ). Immunoprecipitations were performed using $30 \mu \mathrm{l}$ of anti-HA agarose (Roche) for $2 \mathrm{~h}$ at $4{ }^{\circ} \mathrm{C}$ with gentle agitation. For enzymatic digestions, immunoprecipitates were denatured in glycoprotein denaturing buffer ( $0.5 \%$ SDS, $1 \% 2$-mercaptoethanol) at $95{ }^{\circ} \mathrm{C}$ for $5 \mathrm{~min}$, followed by addition of sodium 
citrate (pH 5.5) to a final concentration of $50 \mathrm{mM}$, and incubated with endoglycosidaseH (New England Biolabs) at $37^{\circ} \mathrm{C}$ for $2 \mathrm{~h}$. Immune complexes were eluted by boiling in reducing sample buffer, subjected to SDS-PAGE (10\%), and visualized by autoradiography. Densitometric quantification of radioactivity was performed on a PhosphorImager (Fujifilm BAS-2500) using Image Reader BAS-2500 V1.8 software (Fujifilm) and Multi Gauge V2.2 (Fujifilm) software for analysis. Quantification of human TIM-3 in pulse-chase metabolic labelling was calculated by the following formula representing the average of 2-4 data sets: (human TIM-3 signal intensity - M2 protein signal intensity/M2 protein signal intensity).

\section{Transduction of primary human T cells with shRNA lentiviral vectors to silence human TIM-3}

Lentiviral vectors encoding short hairpin RNAs (shRNAs) (pLKO.1) targeting human TIM3 and a control shRNA targeting lac $Z$ were obtained from the Dana Farber DNA Resource Core. Lentiviral particles were produced as previously described ${ }^{36}$. Primary human $C D 4^{+} \mathrm{T}$ cells were transduced 3 days after stimulation and selected with $2 \mu \mathrm{g} \mathrm{ml}^{-1}$ puromycin (Sigma) for 5 days followed by gradual increases of puromycin $\left(5 \mu \mathrm{g} \mathrm{ml}^{-1}\right)$ for the next 5 days and re-stimulated with anti-CD3 and CD28 for an additional 5 days. TIM3 shRNA1 (TRCN0000158033, 5'-C GTGGACCAAACTGAAGCTAT-3'); TIM3 shRNA 2 (TRCN0000154618, 5'-G CACTGAACTTAAACAGGCAT-3'); TIM3 shRNA 3 (TRCN0000157816, 5'-C AAATGCAGTAGCAGAGGGAA-3'); lacZ control knockdown (TRCN0000072225; 5'-CTCTGGCTAACGGTACGCGTA-3').

\section{Transduction of primary mouse $\mathrm{T}$ cells with retroviral vectors}

For transduction of mouse primary $\mathrm{CD} 4^{+} \mathrm{T}$ cells, previously described mouse TIM-3 and its mutant expressing retroviruses were prepared in HEK293T cells using eco and gag/pol viral envelope constructs (Clontech Inc.) ${ }^{17,37,38}$. Viral supernatants were collected $48 \mathrm{~h}$ after transfection and centrifuged and filtered with a $0.45-\mu \mathrm{m}$ filters. CD $4^{+} \mathrm{T}$ cells were prepared at $10^{6}$ cells per $\mathrm{ml}$ in the presence of polybrene (Sigma; $8 \mathrm{mg} \mathrm{ml}^{-1}$ ). Viral particles and $\mathrm{CD}^{+} \mathrm{T}$ cells were co-incubated by spin inoculation at 2,000 $\mathrm{g}$ for $60 \mathrm{~min}$ on two sequential days. To detect ectopic expression of the constructs in T cells, cells were allowed to rest for 3 days in $2 \mathrm{ng} \mathrm{ml}^{-1} \mathrm{IL}-2$ and sorted to obtain cells with the highest (45\%) GFP expression. Sorted cells were titrated into in vitro T-cell assays.

\section{Galectin-9 induction of a poptosis}

Naive $\mathrm{CD} 4^{+} \mathrm{T}$ cells were polarized under $\mathrm{T}_{\mathrm{H}} 1$ inducing conditions. In brief, naive $\mathrm{CD} 4^{+} \mathrm{T}$ cells $\left(2 \times 10^{6}\right.$ per $\left.\mathrm{ml}\right)$ were stimulated with plate-bound anti-CD3 specific antibodies $(10 \mu \mathrm{g}$ $\left.\mathrm{ml}^{-1}\right)$ for $48 \mathrm{~h}$. Soluble anti-CD28 antibodies $\left(1 \mu \mathrm{g} \mathrm{m}{ }^{-1}\right)$, recombinant (r) IL-2 $\left(10 \mathrm{ng} \mathrm{m}^{-1}\right.$, $\mathrm{NIH})$ and blocking antibodies to IL-4 $\left(10 \mu \mathrm{g} \mathrm{ml}^{-1}\right)$ and rIL-12 $\left(5 \mathrm{ng} \mathrm{ml}^{-1}\right)$ were added and the cells cultured for 7 days. Cells were washed and treated with galectin-9 $\left(2 \mu \mathrm{g} \mathrm{ml}^{-1}\right.$; eBioscience) for $8 \mathrm{~h}$ to induce apoptosis. Apoptosis was detected by flow cytometry using apoptosis staining kit (Roche) that stains for annexin $\mathrm{V}$ and propidium idodide. 


\section{Protein purification, crystallization, X-ray data collection and model determination}

Competent E. coli BL21 DE3 cells were transformed with a pET9a vector carrying a gene insert coding for a single-chain of a protein consisting of the human CEACAM1 IgV domain (residues 1-107), a 20 amino acid linker (4 repeats of a Gly-Gly-Gly-Gly-Ser motif), and the human $\operatorname{IgV}$ domain of TIM-3 (residues 1-105) with a hexa-histidine tag appended to the $\mathrm{C}$ terminus. To express the protein, trans-formants were grown in 1 litre of LB broth under antibiotic selection and induced with $0.1 \mathrm{mM}$ isopropyl- $\beta$-o-thiogalactoside (IPTG) after reaching an absorbance at $600 \mathrm{~nm}\left(A_{600 \mathrm{~nm}}\right)$ of approximately 0.8 . Cells were grown for an additional 16 hat $18{ }^{\circ} \mathrm{C}$ and collected by centrifugation. Protein was purified from inclusion bodies, which were solubilized in a chaotropic buffer and refolded in a buffer containing $200 \mathrm{mM}$ Tris, $\mathrm{pH} 8.5,0.4 \mathrm{M}$ arginine-HCl, $2 \mathrm{mM}$ EDTA, $5 \mathrm{mM}$ cysteamine and $0.5 \mathrm{mM}$ cystamine, as reported previously ${ }^{39}$. Refolded protein was loaded onto a Ni-NTA affinity column and washed several times with a buffer containing $50 \mathrm{mM}$ HEPES, pH7.5, $300 \mathrm{mM} \mathrm{NaCl}, 2.5 \mathrm{mM} \mathrm{CaCl}_{2}, 10 \%$ glycerol and $10-30 \mathrm{mM}$ imidazole. The protein was eluted with $50 \mathrm{mM}$ HEPES buffer, pH7.2, $300 \mathrm{mM} \mathrm{NaCl}, 2.5 \mathrm{mM} \mathrm{CaCl}_{2}, 10 \%$ glycerol and $300 \mathrm{mM}$ imidazole. Eluted protein fractions were analysed by SDS-PAGE, pooled, concentrated and further purified with a Superdex 75 gel filtration column (GE Healthcare) in a buffer containing $50 \mathrm{mM}$ HEPES buffer, pH7.5, $200 \mathrm{mM} \mathrm{NaCl}, 2.5 \mathrm{mM} \mathrm{CaCl}_{2}$ and $10 \%$ glycerol. Circular dichroism was conducted to confirm proper protein folding. Purified protein (purity $>95 \%$, estimated by SDS-PAGE) was concentrated to $2.5 \mathrm{mg} \mathrm{ml}^{-1}$ for crystallization.

The initial crystal growth trials were performed by vapour diffusion using a Phoenix robotic system (Art Robbins) with Index Screens 1 and 2 (Hampton Research) and optimized using an additive screen (Hampton Research). Optimized crystals were formed in $4 \mu \mathrm{l}$ drops ( $2 \mu \mathrm{l}$ protein, $2 \mu \mathrm{l}$ mother liquor), equilibrated against a mother liquor containing $100 \mathrm{mM}$ Tris 8.0 and 25\% PEG 3350, at room temperature in a sitting drop setup. For data collection, crystals were cryoprotected in solution containing 25\% PEG 3350 and $12 \%$ glycerol. X-ray data were collected using the X25 beamline at the National Synchrotron Light Source (NSLS). The data were processed with $\mathrm{Mosflm}^{40}$ and the CCP4 software suite ${ }^{41}$.

A crystallographic model of the single-chain human CEACAM1-TIM-3 protein was built by a molecular replacement strategy using a search model made by modifying published structures of the $\mathrm{IgV}(\mathrm{N})$ domain of human CEACAM1 (Protein Data Bank (PDB) code 2GK2) and mouse TIM-3 (PDB code 2OYP). Specifically, all residues were changed to alanine to reduce model bias and all small molecule ligands, water and metals were removed. Molecular replacement was performed with the program Molrep. Model building and structural refinement were performed with the PHENIX software ${ }^{42}$ and COOT $^{43}$, respectively. Five per cent of the total reflection data were excluded from the refinement cycles and used to calculate the free $R$ factor $\left(R_{\text {free }}\right)$ for monitoring refinement progress. Repeated rounds of model building and refinement with group B-factors refinement strategy and Torsion-NCS restraints resulted in a final crystallographic $R_{\text {work }} / R_{\text {free }}$ of $34.5 \% / 37.3 \%$ using all data to $3.4 \AA$ resolution. The X-ray data and refinement statistics are shown in Extended Data Table 2. Most of the residues were well defined and verified by PDB validation report (data not shown). However, the $\beta$-strands associated with the hTIM-3 AB- 
ED (ref. 13) face did not show the secondary structure of $\beta$-sheet formation, and two disulphide bonds (Cys 32-Cys 110 and Cys 53-Cys 62) observed in the mouse TIM-3 structure were missing from the resolved structure. A $2 F_{\mathrm{o}}-F_{\mathrm{c}}$ electron density map of the human CEACAM1 (IgV)-TIM-3 (IgV) single chain was calculated using PHENIX. All the figures were drawn using PyMOL (The PyMOL Molecular Graphics System, Schrödinger, LLC) and labels were added using Adobe Photoshop.

\section{Protein purification, crystallization, data collection and structure determination of CEACAM1 (IgV)}

Competent $E$. coli BL21 DE3 cells were transformed with a pET9a vector carrying the human CEACAM1 IgV domain gene insert with a N-terminal GST tag. To express the protein, transformants were grown in 1 litre of LB broth under antibiotic selection and induced with $0.1 \mathrm{mM}$ IPTG after reaching an $A_{600 \mathrm{~nm}}$ of approximately 0.8 . Cells were grown for an additional $16 \mathrm{~h}$ at $18{ }^{\circ} \mathrm{C}$ and collected by centrifugation. Cell pellets were suspended in $20 \mathrm{mM}$ Tris- $\mathrm{HCl}$ buffer, $\mathrm{pH} 7.5$, containing $150 \mathrm{mM} \mathrm{NaCl}$ and $10 \%$ glycerol, and lysed by sonication. After centrifugation, supernatant was loaded onto a GST column (GE Healthcare) and washed several times with $50 \mathrm{mM}$ Tris-HCl buffer, $\mathrm{pH} 7.5$, containing $150 \mathrm{mM} \mathrm{NaCl}, 2.5 \mathrm{mM} \mathrm{CaCl}_{2}, 0.1 \%$ Triton X-100, and 10\% glycerol. After on-column removal of the GST affinity tag with thrombin, protein was eluted with $25 \mathrm{mM}$ Tris- $\mathrm{HCl}$ buffer, pH7.5, containing $200 \mathrm{mM} \mathrm{NaCl}, 2.5 \mathrm{mM} \mathrm{CaCl}_{2}$ and $10 \%$ glycerol. Eluted protein fractions, as judged by SDS-PAGE, were concentrated and purified through a Superdex 75 gel filtration column (GE Healthcare) by FPLC system with a buffer containing $50 \mathrm{mM}$ Tris- $\mathrm{HCl}$ buffer, $\mathrm{pH} 7.5$, containing $200 \mathrm{mM} \mathrm{NaCl}, 2.5 \mathrm{mM} \mathrm{CaCl}_{2}$ and $10 \%$ glycerol. A single peak for human CEACAM1 IgV domain was collected and the protein was concentrated to $5 \mathrm{mg} \mathrm{ml}^{-1}$ for crystallization. A purity of $>95 \%$, was verified by SDSPAGE.

The initial crystal growth trials were performed in a 96-well format using a Phoenix robotic system (Art Robbins) with Index Screens 1 and 2 (Hampton Research) at room temperature. Optimized crystals were formed in well solution containing $60 \%$ Tascimate, $\mathrm{pH} 8$, and $1 \% \beta$ octyl glucoside at room temperature. For data collection, crystals were cryoprotected in solution containing $60 \%$ Tascimate, $\mathrm{pH} 8$ and $18 \%$ glycerol. X-ray data were collected using beamline X6A at the National Synchrotron Light Source (NSLS). The data were processed with Mosflm ${ }^{40}$ and the CCP4 software suite ${ }^{41}$. The structure of the human CEACAM1 N (IgV) domain was determined by the molecular replacement method using a modified $\mathrm{N}$ terminal domain of human CEACAM1 as a search model (PDB code 2GK2) as the starting model, with all residues changed to alanine to reduce model bias and all small molecule ligands, water and metals were removed. Molecular replacement was performed with Molrep, refinements were performed with PHENIX ${ }^{42}$ and intermittent model building was performed with $\mathrm{COOT}^{43}$, as described above. Subsequent refinements cycles and model building with individual B-factors and Torsion-NCS restraints strategy led to the final crystallographic $R_{\text {work }} / R_{\text {free }}$ of $20.3 \% / 24.2 \%$ using all data to $2.0 \AA$ resolution. Electron densities were also identified for bound molecules of beta-octyl glucoside and malonic acid. The X-ray data and structure refinement statistics are shown in Extended Data Table 2. All 
residues were well defined and verified by PDB validation report (data not shown). A $2 F_{\mathrm{O}}-$ $F_{\mathrm{c}}$ electron density map was calculated using PHENIX ${ }^{42}$.

\section{Structural modelling of CEACAM1-TIM-3 interactions}

To model potential interactions between CEACAM1 and TIM-3, superimposition data as shown in Extended Data Fig. 2d, e, of previously described immunoglobulin-variable (IgV) domains of mouse CEACAM $1^{14}$ (PDB code 1L62) and mouse TIM-3 (PDB 2OYP) ${ }^{13}$ was generated in Pymol (The PyMOL Molecular Graphics System, Schrödinger, LLC), which revealed structural similarity as shown by a score of 2.42 by root mean square deviation (r.m.s.d.) analysis as calculated by Pymol ${ }^{44}$. In addition, multiple sequence alignments were performed using ClustalW ${ }^{45}$. From this analysis, we considered mouse CEACAM1 and TIM-3 as structurally similar proteins. Furthermore, as previous structural data for mouse CEACAM1 supported the formation of CEACAM1 homodimers between its N-terminal domains ${ }^{14}$, and given our evidence that mouse CEACAM1 and TIM-3 are highly similar, we further reasoned that mouse TIM-3 and its human orthologue might heterodimerize with CEACAM1 through their membrane-distal N-terminal domains. This hypothesis was modelled by us in the following manner. We aligned CEACAM1 symmetrically for cis modelling and asymmetrically for trans modelling along the five amino acid residues within the FG-CC' loops of mTIM-3 as reported previously ${ }^{13}$ that describe putative docking sites for an unknown ligand for mouse TIM-3. The ROSIE Docking Server was used to analyse the docking (http://rosettadock.graylab.jhu.edu/documentation/docking) ${ }^{46,47}$. We identified the ten best scoring structures from the run in rank order by energy. The top two in cis and the best in trans are shown in Extended Data Fig. 2g. The score ( $y$ axis) indicates the energy of the models (the lower the better). The r.m.s. ( $x$ axis) indicates the RMS values between the input and output docking models. The docking models identified were further assessed in PyMOL to determine whether the models identified predicted hydrogen bonding within the putative mouse CEACAM1-TIM-3 interface. On the basis of this we identified potential amino acids that may have an important role in mouse CEACAM1- TIM-3 binding, which is summarized in the table associated with Extended Data Fig. 2g.

We used the amino acids of mouse CEACAM1 and mouse TIM-3 modelled at the interface between these two proteins to predict potential contact sites for the human orthologues of CEACAM1 and TIM-3. Furthermore, we searched human exomic databases for allelic variants in these predicted human amino acids. Finally, we used all of this information to make structural modifications of human CEACAM1 and TIM-3 by site-directed mutagenesis to biochemically examine our hypothesis and confirm this by X-ray crystallographic analysis of a human CEACAM1-TIM-3 single-chain protein.

\section{IBD case-control samples and genotyping}

German Crohn's disease and ulcerative colitis patients were recruited at the Department of General Internal Medicine of the Christian-Albrechts- University Kiel and Charité Universitätsmedizin Berlin, or nationwide with the support of the German Crohn and Colitis Foundation and the Bundesministerium für Bildung und Forschung (BMBF) competence network 'IBD' (Extended Data Table 3a). The patients were classified according to clinical, radiological, histological and endoscopic (that is, type and distribution of lesions) according 
to accepted criteria ${ }^{48,49}$. Healthy control individuals were obtained from the popgen biobank $^{50}$. All controls were drawn from a population-representative sample. Given the low prevalence of both Crohn's disease and ulcerative colitis and the fact that all control individuals self-reported to have neither Crohn's disease nor ulcerative colitis, control individuals were designated 'healthy'. Written, informed consent was obtained from all study participants and all protocols were approved by the institutional ethical review committees of the participating centres. The variants described in Extended Data Table $3 \mathrm{~b}$ were genotyped using the Sequenom iPlex and the Life Technologies Taqman system. rs147827860, the single nucleotide polymorphism encoding the hypomorphic Thr101Ile allele of TIM3, is a rare variant with a minor allele frequency of 0.004 in individuals of European descent predicting homozygous carriage with a frequency of 0.000016 (or 1:62,500). None of the publicly accessible databases lists any homozygous occurrences of this variant. Association in the case-control data was tested with Haploview 4.2 (ref. 51). An exact test for Hardy-Weinberg equilibrium was performed using the DeFinetti program (Strom, T. M. \& Wienker, T. F., http://ihg.gsf.de/cgi-bin/hw/hwa1.pl).

\section{Purification of $\operatorname{lgV}$ domain of human TIM-3}

The TIM-3 IgV domain was expressed with a C-terminal GST tag as inclusion bodies from pET9a in E. coli BL21 DE3 cells. Inclusion bodies were refolded as described previously in refolding buffer containing $200 \mathrm{mM}$ Tris, pH8.5, 0.4M arginine- $\mathrm{HCl}, 2 \mathrm{mM}$ EDTA, $5 \mathrm{mM}$ cysteamine and $0.5 \mathrm{mM}$ cystamine ${ }^{39}$. Refolded proteins were purified by affinity and gel filtration chromatography. The proteins were maintained in a solution containing $25 \mathrm{mM}$ HEPES buffer, $\mathrm{pH} 7.2$, containing $200 \mathrm{mM} \mathrm{NaCl}, 2.5 \mathrm{mM} \mathrm{CaCl}_{2}$ and $5 \%$ glycerol. Circular dichroism was conducted to ascertain proper protein folding. A purity of $>95 \%$, was verified by SDS-PAGE.

\section{GST protein pull-down assays}

Glutathione-S-transferase (GST) pull-down analyses ${ }^{52}$ of the interaction between IgV domains of human TIM-3 and human CEACAM1 were performed in the following manner. The GST-hTIM-3 protein was stored in refolding buffer, and buffer-exchanged with PBS before performing the assay. The IgV domain of GST-hTIM-3 proteins were coupled to the glutathione-agarose column following the manufacturer's instructions (Thermo scientific) and in-column-incubated with HEK293T cell lysates derived from cells transfected with Flag-tagged human CEACAM1. The columns were washed extensively and bound proteins were eluted by glutathione. Eluted protein complexes were immunoblotted for the detection of CEACAM1 (immunoblot with anti-Flag) and TIM-3 (immunoblot with anti-GST).

\section{TIM-3 ligand precipitation assays}

Extracellular membrane-associated proteins on live TK-1 cells were labelled with biotin (EZ-LinkSulfo-NHS-LC-Biotin; Pierce). Whole-cell lysates were prepared and were incubated with $5 \mu \mathrm{g}$ human IgG, full length TIM-3-Ig or soluble(s) TIM-3-Ig in the presence of protein $\mathrm{G}-$ agarose beads (Roche). Beads were washed and boiled with $1 \times$ SDSPAGE loading buffer. Supernatants were collected by centrifugation, and half of each was digested with PNGase F (New England Biolabs). Samples were separated by SDS-PAGE 
and the TIM-3-Ig fusion protein-specific binding proteins were detected by immunoblot or sliver staining.

\section{Mouse model of IBD 53}

Splenic mononuclear cells were obtained from female wild-type, Ceacam1 ${ }^{-1-}$, Ceacam-4L ${ }^{\text {Tg }}$ Ceacam1 $^{-/-}$, Tim3 ${ }^{\text {Tg }}$ Ceacam1 $^{-/-}$, Tim $3^{\text {Tg }}$ Ceacam1 $^{+/+}$(Tim3 $3^{\text {Tg } / \text { wild-type })}$ mice and $\mathrm{CD}^{+} \mathrm{T}$ cells were isolated using anti-CD4 (L3T4) MACS magnetic beads (Miltenyi Biotec) according to the manufacturer's instructions. Enriched CD4 ${ }^{+} \mathrm{T}$ cells (9497\% pure as estimated by FACS) were then labelled with PerCP-conjugated anti-CD4, allophycocyanin-conjugated anti-CD44, and FITC-conjugated anti-CD62L and phycoerythrin-conjugated anti-TIM-3 (5D12 or 2C12). Subpopulations of CD4 ${ }^{+} \mathrm{T}$ cells were identified by three-colour sorting on a FACSAria (Becton Dickinson). All populations were defined as naive and $98.0 \%$ pure on re-analysis. To induce chronic colitis in animals, 5 $\times 10^{5} \mathrm{CD} 4{ }^{+} \mathrm{CD} 44^{10} \mathrm{CD} 62 \mathrm{~L}^{\text {high }}$ (naive) $\mathrm{T}$ cells were adoptively transferred intraperitoneally into 6-10-week-old Ceacaml ${ }^{-1-} \mathrm{Rag}^{-/-}$recipient mice. Weights were measured every week, and mice were euthanized by $\mathrm{CO}_{2}$ for histological evaluation of colitis and lamina propria mononuclear cells. Owing to the severity of colitis associated with adoptive transfer of naive Ceacam1 $1^{-/} \mathrm{CD}^{+} \mathrm{T}$ cells, significant mortality was observed resulting in unequal group size at the at the time of culling necessitating post-hoc correction in the statistical analysis (see 'statistical methods').

\section{Colorectal carcinogenesis models}

To examine the effect of CEACAM1 and TIM-3 on tumour incidence and multiplicity in an inflammation induced colorectal cancer model, mice were intraperitoneally injected at 6 weeks of age with the carcinogen AOM (Sigma-Aldrich) at $10 \mathrm{mg} \mathrm{kg}^{-1}$ body weight as previously reported ${ }^{54,55}$. One week later, the mice were started on the first of two 21-day DSS cycles, consisting of a period of 7 days with the tumour promoter DSS at $2.5 \%$ or $1.5 \%$ in the drinking water followed by 7 days of receiving regular water. Mice showing signs of morbidity were culled. Colons were removed and flushed with PBS buffer and cut longitudinally. Colon tissue sections were either paraffin-embedded for immunohistochemistry or analysis of lamina propria mononuclear cells associated with the tumours. CT26 colorectal carcinoma cells were diluted into $10 \times 10^{6}$ cells per ml of PBS. After shaving, either wild-type or Ceacam ${ }^{-1-}$ mice received $200 \mu \mathrm{l}$ of the CT26 cell suspension subcutaneously in the left flank. All antibody treatments were applied intraperitoneally into the right flank according to the schedules described in Extended Data. Two-hundred micrograms of each antibody or its isotype control were administered according to the schedules described (CEACAM1, cc1 clone; TIM-3 5D12 clone; PDL1, 10F.9G2) Tumour growth was assessed three times per week at 7 days after tumour inoculation by measuring the width and length of the tumours $(\mathrm{mm})$ using calipers and the areas defined $\left(\mathrm{mm}^{2}\right.$; width $\times$ length). Mice were euthanized on the basis of the extent of tumour growth observed in the isotype antibody treated control animals to minimize animal suffering in accordance with the approved animal protocol. 


\section{Histopathological examination of colitis and colitis-associated colorectal cancer}

Colons were removed from mice after termination and dissected free from the anus to the caecum. Colonic contents were removed and colons cleaned with PBS before fixation in $4 \%$ paraformaldyhyde or $10 \%$ neutral buffered formalin followed by routine paraffin embedding. After paraffin embedding, 0.5-mm sections were cut and stained with haematoxylin and eosin. Sections were examined and colitis was scored in a blinded fashion (with respect to genotype and experimental protocol) by one of the authors (J.N.G.). Each of four histological parameters for the severity of colitis was scored as absent (0), mild to severe (1-6): mononuclear cell infiltration, polymorphonuclear cell infiltration, epithelial hyperplasia, epithelial injury and extent of inflammation, modified from a previous study ${ }^{56}$. For AOM/DSS, colitis-associated colorectal cancer studies, an expert pathologist (J.N.G.) examined all tissues for dysplasia, adenoma, low-to-high-grade adenoma and adenocarcinoma in a blinded fashion.

\section{RNA, complementary DNA and quantitative PCR}

RNA was isolated from whole cells using the Qiagen microRNA extraction kit following the manufacturer's instructions. RNA was quantified spectrophotometrically, and complementary DNA was reverse-transcribed using the cDNA archival kit (Applied Biosystems) following the manufacturer's guidelines. All primers were obtained from Applied Biosystem. The cDNA samples were subjected to 40 cycles of amplification in an ABI Prism 7900 Sequence Detection System instrument according to the manufacturer's protocol. Quantification of relative messenger RNA expression was determined by the comparative $C_{\mathrm{t}}$ (critical threshold) method as described whereby the amount of target mRNA, normalized to endogenous cycles of amplification was determined by the formula $2^{-\Delta \Delta C \mathrm{t}}$.

\section{Gene expression analyses by NanoString}

Naive T cells from wild-type, $\operatorname{Tim}^{\mathrm{Tg}}$ and $\operatorname{Tim}^{\mathrm{Tg}} \mathrm{Ceacam}^{-1-}$ mice were transferred into Ceacam I ${ }^{-/}$Rag2 $^{-/}$recipients to induce colitis. For the analyses of transcriptional regulation, colonic infiltrating lamina propria mononuclear cells were isolated at 6 weeks after T-cell transfer and immediately lysed in RLT buffer (Qiagen). For RNA analysis, 100 ng of total RNA was used and hybridized to a custom designed gene CodeSet (nonenzymatic RNA profiling using bar-coded fluorescent probes) according to the manufacturers protocol (Nanostring Technologies). Barcodes were counted (1,150 fields of view per sample) on an nCounter Digital Analyzer following the manufacturer's protocol (NanoString Technologies, Inc.).

\section{Cytokine measurements}

To measure cytokine production by ELISA, $1 \times 10^{5} \mathrm{CD}^{+} \mathrm{T}$ cells were cultured in $200 \mu \mathrm{l}$ RPMI 1640 (Sigma-Aldrich) supplemented with 10\% heat-inactivated FBS, $500 \mathrm{U} \mathrm{ml}^{-1}$ penicillin, $100 \mu \mathrm{g} \mathrm{ml}^{-1}$ streptomycin (Sigma-Aldrich), $10 \mathrm{mM}$ HEPES, $1 \%$ nonessential amino acids and $50 \mu \mathrm{M}$ 2-mercaptoethanol (Life Technologies Invitrogen), which was termed complete RPMI 1640, in the presence of $5 \mu \mathrm{g} \mathrm{ml}^{-1}$ plate-bound anti-CD3 and $2 \mu \mathrm{g}$ $\mathrm{ml}^{-1}$ soluble anti-CD28 monoclonal antibodies on flat-bottom 96-well plates (Costar), at 37 
${ }^{\circ} \mathrm{C}$ in a humidified atmosphere incubator containing $5 \% \mathrm{CO}_{2}$ for $48 \mathrm{~h}$ or otherwise indicated. Culture supernatants were removed and analysed for the production of cytokines such as IFN- $\gamma$, IL-2 or TNF- $\alpha$. Cytokine concentrations were determined using specific ELISAs (R\&D Systems) according to the manufacturer's recommendations. To measure cytokine production by intracellular cytokine staining on colitis-associated $\mathrm{CD} 4^{+} \mathrm{T}$ cells obtained from the dissection of mesenteric lymph nodes, lymph nodes or lamina propria were incubated at $37^{\circ} \mathrm{C}$ for $4-6 \mathrm{~h}$ incomplete RPMI 1640 medium with $50 \mathrm{ng} \mathrm{ml}^{-1}$ PMA (Sigma-Aldrich), $500 \mathrm{ng} \mathrm{ml}^{-1}$ ionomycin (Sigma-Aldrich), and $1 \mu \mathrm{ml}^{-1}$ GolgiPlug (BD). Surface staining was performed for $30 \mathrm{~min}$, after which the cells were resuspended in fixation/permeabilization solution (Cytofix/Cytoperm kit; BD). Intracellular cytokine staining using antibodies as described earlier was performed according to the manufacturer's instructions. To measure cytokine production by intracellular cytokine staining in draining lymph node $\mathrm{CD}^{+}{ }^{+}$or $\mathrm{CD} 8^{+} \mathrm{T}$ cells derived from CT26-tumour bearing mice, cells were stimulated with $5 \mu \mathrm{g} \mathrm{ml}^{-1}$ AH1-peptide (SPSYVYHQF) or tumour-infiltrating lymphocytes (TIL) with $1 \mu \mathrm{g} \mathrm{ml}^{-1}$ plate-bound monoclonal antibody (mouse anti-CD3 antibody for $48 \mathrm{~h}$ ). The cells were counterstained with monoclonal antibody against CD8-FITC with or without AH1-tetramer (Medical Biological Laboratories) which detects the MuLV gp70 peptide (SPSYVYHQF) in the context of $\mathrm{H}-2 \mathrm{~L}^{\mathrm{d}}$ and analysed by flow cytometry.

\section{Surface plasmon resonance}

Studies were performed on Biacore 3000 (GE Healthcare). GST-hTIM-3 protein, or GST alone as control, was immobilized on a CM5 sensor chip using amine coupling chemistry as per the manufacturer's instructions. The coupling was performed by injecting $30 \mathrm{~g} \mathrm{ml}^{-1}$ of protein into $10 \mathrm{mM}$ sodium acetate, pH5.0 (GE Healthcare). HBS-EP buffer (0.01 M HEPES, $0.15 \mathrm{M} \mathrm{NaCl}, 3 \mathrm{mM}$ EDTA, $0.005 \%$ surfactant P20; GE Healthcare) was used as running buffer and dilution buffer. Serial dilutions of analytes in HBS-EP were injected at $25^{\circ} \mathrm{C}$ with a $25 \mu \mathrm{min}^{-1}$ flow rate and data collected over time. The surface was regenerated between different dilutions with $10 \mathrm{mM}$ glycine-HCl, pH2.5 (GE Healthcare). For blockade of single-chain binding to GST-hTIM-3, single-chain hCEACAM1-hTIM-3 protein was injected alone or together with antibody (anti-human CEACAM1 monoclonal antibody, 26H7) or TIM-3-specific peptide (residues 58-77, 58-CPV

FECGNVVLRTDERDVNY-77) with IgG1 mouse antibody or scrambled peptide (TLCVCFVNPYDVRVNDEREG) used as controls, respectively. All data were zero adjusted, and the reference cell value was subtracted.

\section{Isolation of lamina propia mononuclear cells and TILs}

Colonic lamina propria mononuclear cells, colonic polyp-derived TILs and subcutaneous CT26 derived TILs were isolated as follows. Total colons from each group were longitudinally cut and washed with HBSS (free of $\mathrm{Ca}^{2+}$ and $\mathrm{Mg}^{2+}$ ) to remove faeces and debris. Subcutaneous CT26 tumours were dissected and dissociated in a gentle MACS dissociator (Miltenyi Biotec). Tumours, tumour-free colon pieces and CT26 tumour pieces were further finely minced and incubated in HBSS containing $5 \mathrm{mM}$ EDTA, $0.145 \mathrm{mg} \mathrm{ml}^{-1}$ dithiothreitol, $1 \mathrm{M}$ HEPES, $10 \% \mathrm{FBS}$, and $1 \%$ penicillin/streptomycin at $37{ }^{\circ} \mathrm{C}$ for $15 \mathrm{~min}$ for two cycles to dissociate the epithelial monolayers. EDTA was then removed by three washes in HBSS. The colon tissue and tumour specimens then were digested in RPMI 1640 
containing $0.4 \mathrm{mg} \mathrm{ml}^{-1}$ collagenase $\mathrm{D}$ (Roche) and $0.01 \mathrm{mg} \mathrm{ml}^{-1}$ DNase I (Roche) for 20 $\mathrm{min}$ (tumour-free colon pieces) or $30 \mathrm{~min}$ (tumour pieces) at $37^{\circ} \mathrm{C}$ on a shaking platform and further digested with collagenase IV (Roche) at $0.01 \mathrm{mg} \mathrm{ml}^{-1}$ DNase I (Roche) for 20 min (tumour-free colon pieces) or $30 \mathrm{~min}$ (tumour pieces) at $37^{\circ} \mathrm{C}$ on a shaking platform. After enzymatic treatment, digested tissue was passed through a 70- $\mu \mathrm{m}$ cell strainer and the flow-through medium containing the mononuclear cells was collected and centrifuged at $400 \mathrm{~g}$ for $10 \mathrm{~min}$ and pelleted and subjected to a 40:80\% Percoll (GE Healthcare) gradient followed by centrifugation for $20 \mathrm{~min}$ at 2,500 r.p.m. at room temperature. Lamina propria mononuclear cells or TILs were collected at the interphase of the gradient, washed once, and resuspended in RPMI 1640 complete medium for further analyses.

\section{Statistical methods}

Standard two-tailed $t$-test was applied throughout except for the following exceptions. A Welch $t$-test was applied in the setting of unequal variance. The Mann-Whitney $U$ test was applied when data were demonstrated to not follow a Gaussian distribution. In experiments where more than two groups were compared, one-way analysis of variance (ANOVA) was performed followed by application of post-hoc correction using Bonferroni's multiple comparison test or Dunnett's correction followed by Friedman test. Kruskal-Wallis with post-hoc Dunn's correction was used in making multiple comparisons of groups with unequal size. Comparisons of mortality were made by Kaplan-Meier survival curve analysis with log-rank test to assess differences in cancer survival. Pearson's coefficient for correlation $(r)$ test was performed for comparison of variables. GraphPad Prism version 5.0b was used for calculations. $P$ values of 0.05 were considered significant. 


\section{Extended Data}
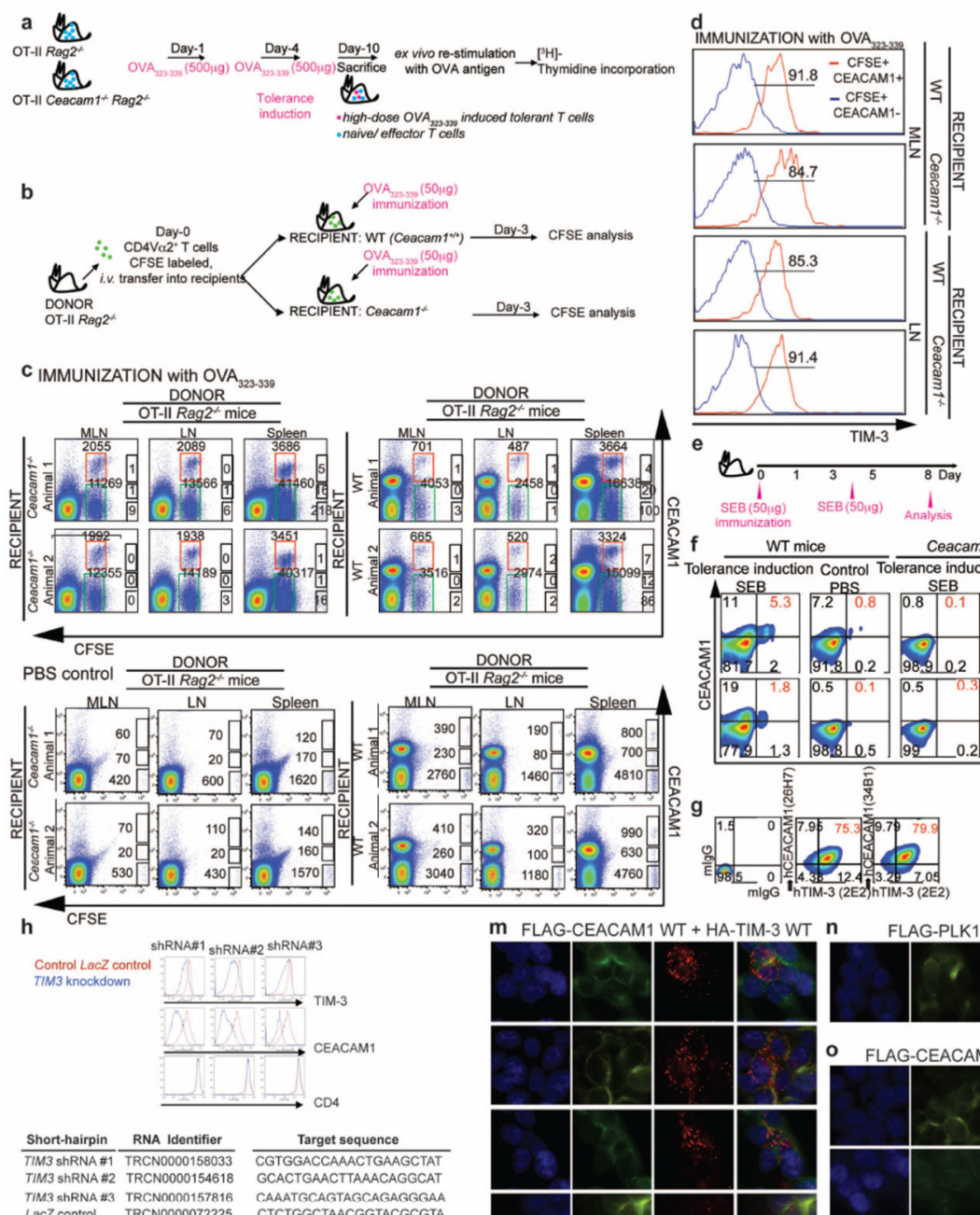

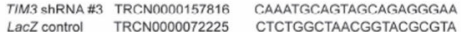
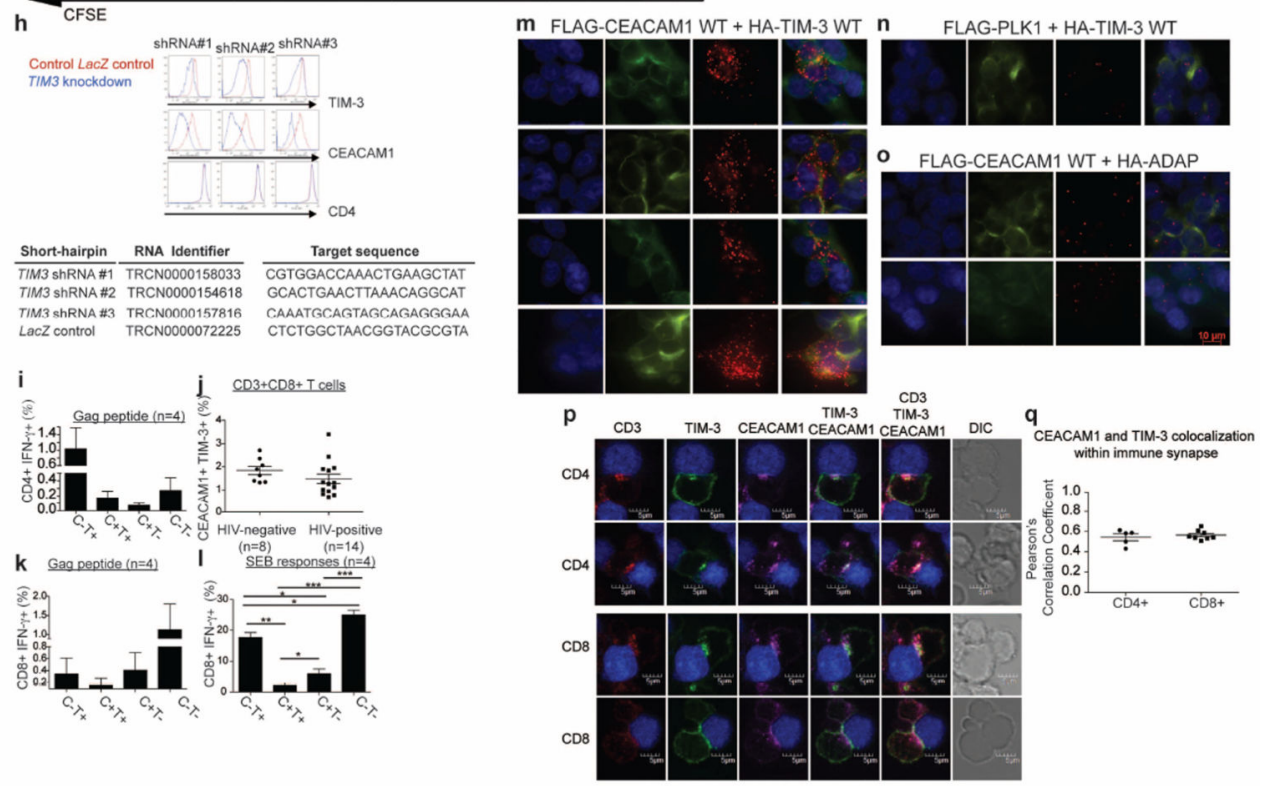

Extended Data Figure 1. CEACAM1 is essential for TIM-3 mediated T cell tolerance a, Schematic diagram of OVA antigen-specific tolerance induction model. $\mathbf{b}$, Schematic diagram of OVA immunization. c, Tracking in vivo antigen-specific T-cell responses of CFSE-labelled OT-II transgenic Rag2-/-T cells in total lymphocyte gate of mesenteric lymph nodes, peripheral lymph node or spleen of wild-type or Ceacam1 ${ }^{-1-}$ recipients after gating on CFSE-positive cells and staining for CEACAM1 in PBS and OVA $323-339$ 


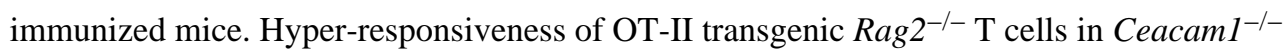
mice was not due to decreased regulatory T-cell induction (data not shown) or increased initial parking on the basis of cell numbers shown. d, TIM-3 expression on CEACAM1positive and -negative $\mathrm{CFSE}^{+}$cells as in c. e, Schematic diagram of SEB-induced T-cell tolerance model. f, mCEACAM1 and mTIM-3 expression on CD4 ${ }^{+} \mathrm{V} \beta 8^{+} \mathrm{T}$ cells after SEB tolerance induction. g, hCEACAM1 and hTIM-3 expression on activated primary human T cells defined by staining with indicated antibodies. $\mathbf{h}$, CEACAM1 expression on TIM-3silenced primary human $\mathrm{T}$ cells after re-activation by flow cytometry. Relative TIM-3, CEACAM1 or CD4 expression on T cells expressing control shRNA (lacZ control, red) or three independent shRNAs directed at TIM3 (overlay, blue). shRNA target sequences shown. $\mathbf{i}-\mathbf{l}, \mathrm{CEACAM} 1$ and TIM-3 expression and functional consequences on $\mathrm{T}$ cells in HIV infection. CD $4^{+}$IFN $-\gamma^{+}$T cells are decreased among CEACAM $1^{+} \mathrm{TIM}_{-} 3^{+} \mathrm{CD} 4^{+} \mathrm{T}$ cells in HIV infection in response to Gag peptides (i). Although proportions of CEACAM1 ${ }^{+}$ TIM- $3^{+} \mathrm{CD} 8^{+} \mathrm{T}$ cells are similar in HIV-infected and -uninfected subjects $(\mathbf{j})$, CEACAM1 ${ }^{+}$ TIM- $3^{+} \mathrm{CD} 8^{+} \mathrm{T}$ cells express little IFN- $\gamma$ after stimulation with HIV Gag peptides or SEB relative to TIM-3 ${ }^{+}$CEACAM1- CD8 ${ }^{+} \mathrm{T}$ cells $(\mathbf{k}, \mathbf{l})$. C, hCEACAM1; T, hTIM-3 $(n=4$ per group, mean \pm s.e.m.). m-o, In situ proximity ligation analysis (PLA) of CEACAM1 and TIM-3. m, HEK293T cells transiently co-transfected with Flag-hCEACAM1 or HAhTIM-3. Cells stained with DAPI (left), anti-tubulin (middle), anti-HA (rabbit) and anti-Flag (mouse) (middle right) or merged (right). Several examples of a positive PLA signal (middle right and right panels: red fluorescent dots) indicative of a maximum distance of 30-40 nm between hCEACAM1 and hTIM-3. n, Negative control, co-expression of Flag-PLK1 (protein kinase I) and HA-TIM-3 failed to generate fluorescent dots (that is, PLA negative). Cells stained with DAPI, anti-tubulin, anti-HA/anti-Flag or merged as in $\mathbf{m . o}$, Negative control, co-expression of HA-ADAP (adhesion and degranulation promoting adaptor protein) failed to show a signal (that is, PLA negative) with staining as in $\mathbf{m} . \mathbf{p}, \mathbf{q}$, CEACAM1 and TIM-3 colocalization at immunological synapse of primary human CD4 and CD8 T cells. Confocal microscopy of hTIM- $3^{+}$hCEACAM $1^{+}$primary CD $4^{+}$and CD8 ${ }^{+}$ T cells forming conjugates with SEB-loaded B cells. DIC, differential interference contrast. Blue denotes B cell; red denotes CD3; purple denotes CEACAM1; green denotes TIM-3. White indicates colocalization between CEACAM1 and TIM-3 (p). Average Pearson correlation coefficients for $\mathrm{CD} 4^{+}$and $\mathrm{CD} 8^{+} \mathrm{T}$ cells were 0.543 and 0.566 , respectively, representing strong co-localization (q). Data are mean \pm s.e.m. and representative of five (f, $\mathbf{g})$, four $(\mathbf{p}, \mathbf{q})$, three $(\mathbf{c}, \mathbf{d}, \mathbf{m}-\mathbf{0})$ and two $(\mathbf{h})$ independent experiments. $* P<0.05 ; * * P<$ $0.01 ; * * * P<0.001$. 


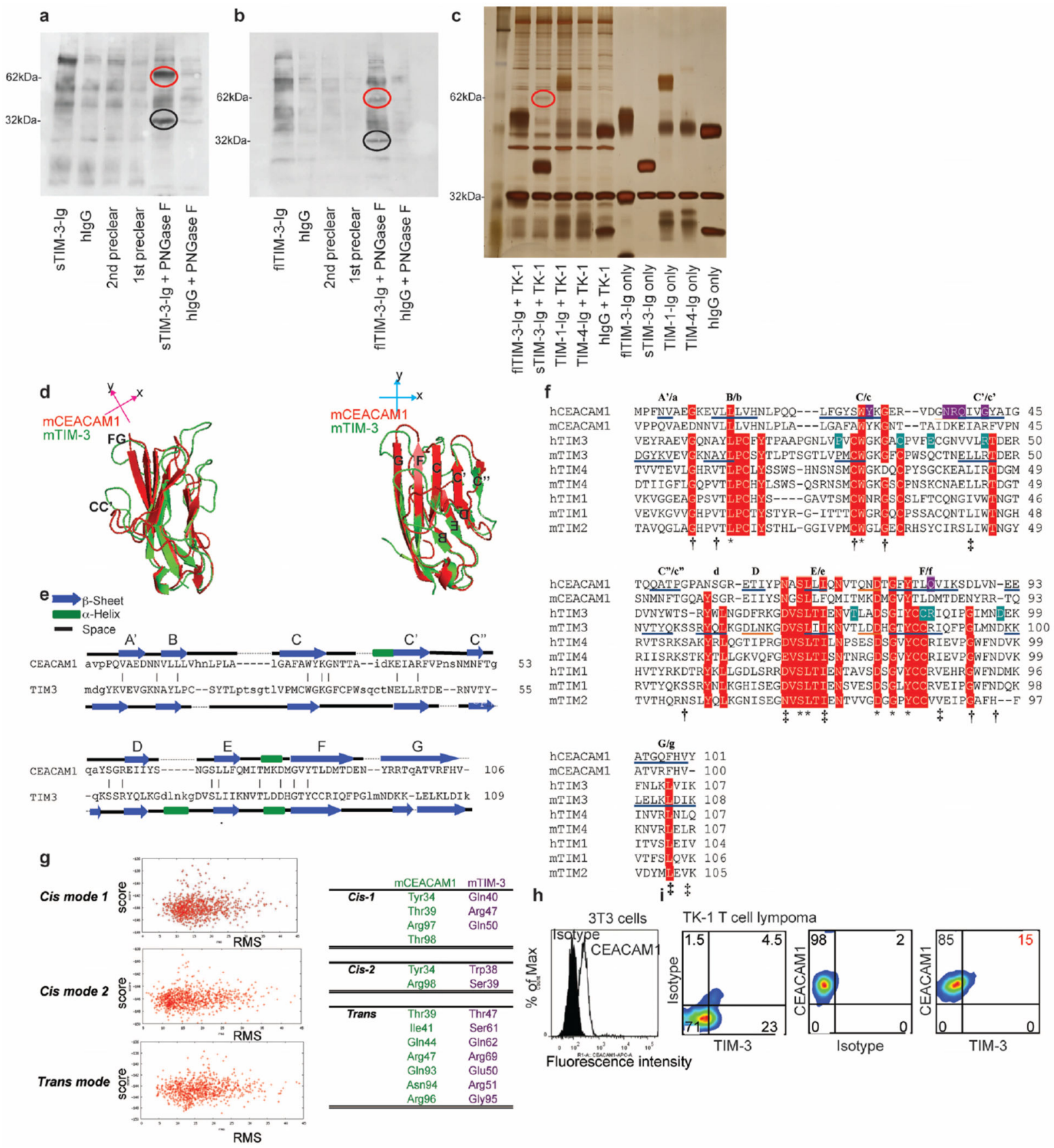

Extended Data Figure 2. Structural similarities between CEACAM1 and TIM-3 IgV-like Nterminal domains and biochemical association

a-c, Interaction between TIM-3-Ig fusion protein and membrane protein of $60 \mathrm{kDa}$ after deglycosylation derived from surface-biotinylated TK-1 cells. TIM-3-Ig fusion proteins and human IgG-precipitated proteins were deglycosylated by PNGase F and separated by SDSPAGE. TIM-3-Ig-binding membrane proteins detected by immunoblot. A 60-kDa membrane protein (red circles) and 32-kDa protein consistent with galectin-9 (black circles) are found specifically associated with soluble (s) TIM-3-Ig fusion protein (a, lane 5) and 
full-length (f) TIM-3-Ig proteins (b, lane 5), but not with the pre-clear controls (lanes 3 and 4) or human IgG (lanes 2 and 6). c, sTIM-3-Ig and full-length (fl) TIM-3-Ig interacting proteins were de-glycosylated by PNGase F and separated by SDS-PAGE. Proteins detected by silver staining. A band of $60 \mathrm{kDa}$ (red circle) isspecifically associated with sTIM-3-Ig proteins (lane 2), but not with human IgG (lane 5), or TIM-1-Ig or TIM-4-Ig (lanes 3, 4, 610). d, Superimposition of previously described IgV-like domains of mCEACAM1 and mTIM-3 demonstrate structural similarity with a score of 2.42 by the structural alignment and root mean square deviation (r.m.s.d.) calculated by Pymol. e, Sequence alignment of the IgV-like domains of mCEACAM1 and mTIM-3 on the basis of the secondary structure alignment in d. f, Sequence alignments of IgV domain sequences of CEACAM1 and overall mTIM and hTIM family members. $\alpha$ helices (orange) and $\beta$ strands (blue) denoted as underlined segments in hCEACAM1 and mTIM-3. $\beta$ strands labelled with upper- and lowercase letters for hCEACAM1 and mTIM-3, respectively. Conserved residues are shaded red. Mutated residues are shaded violet for hCEACAM1, and green for hTIM-3. Asterisk (*) indicates positions having a single, fully conserved residue; a dagger $(\dagger)$ indicates conservation between groups of weakly similar residues; a double-dagger $(\$)$ indicates conservation between groups of strongly similar residues. $\mathbf{g}$, Computational modelling as defined by energy calculations (score) relative to r.m.s. values of docking models to define potential cis and trans interfaces between mCEACAM1 and mTIM-3 as described in Supplementary Information and amino acids involved. $\mathbf{h}$, CEACAM1 expression on mouse fibroblast 3T3 cells used to identify a galectin-9-independent ligand. i, CEACAM1 expression on mouse TK-1 cells as in $\mathbf{a}-\mathbf{c}$. Representative of three $(\mathbf{a}-\mathbf{c}, \mathbf{h}, \mathbf{i})$ independent experiments. 
a

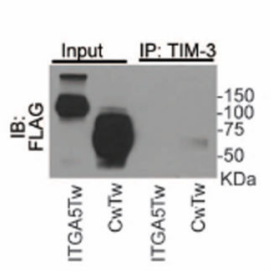

d

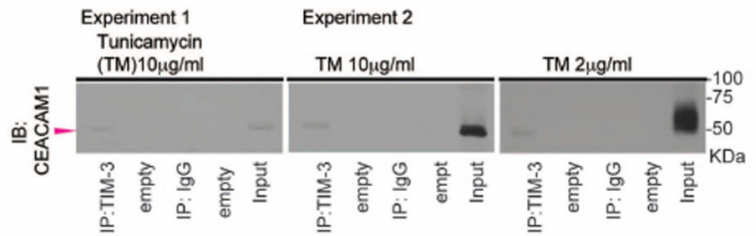

b

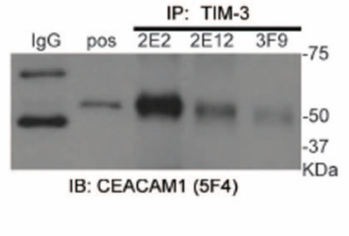

c

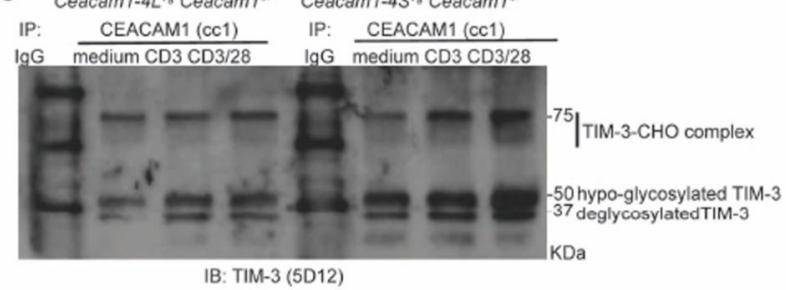

IP. CEACAM1 $10 \mathrm{CC}$

G medium $\mathrm{CD} 3 \mathrm{CD} 3 / 28$ lgG medium $\mathrm{CD} 3 \mathrm{CD} 3 / 28$

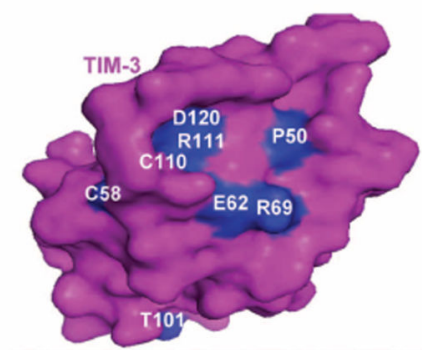

f
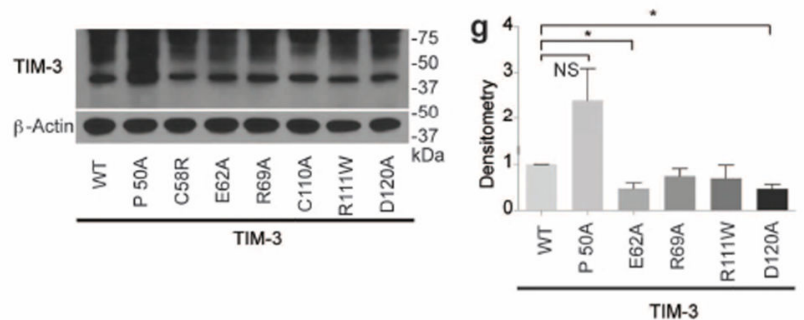

h
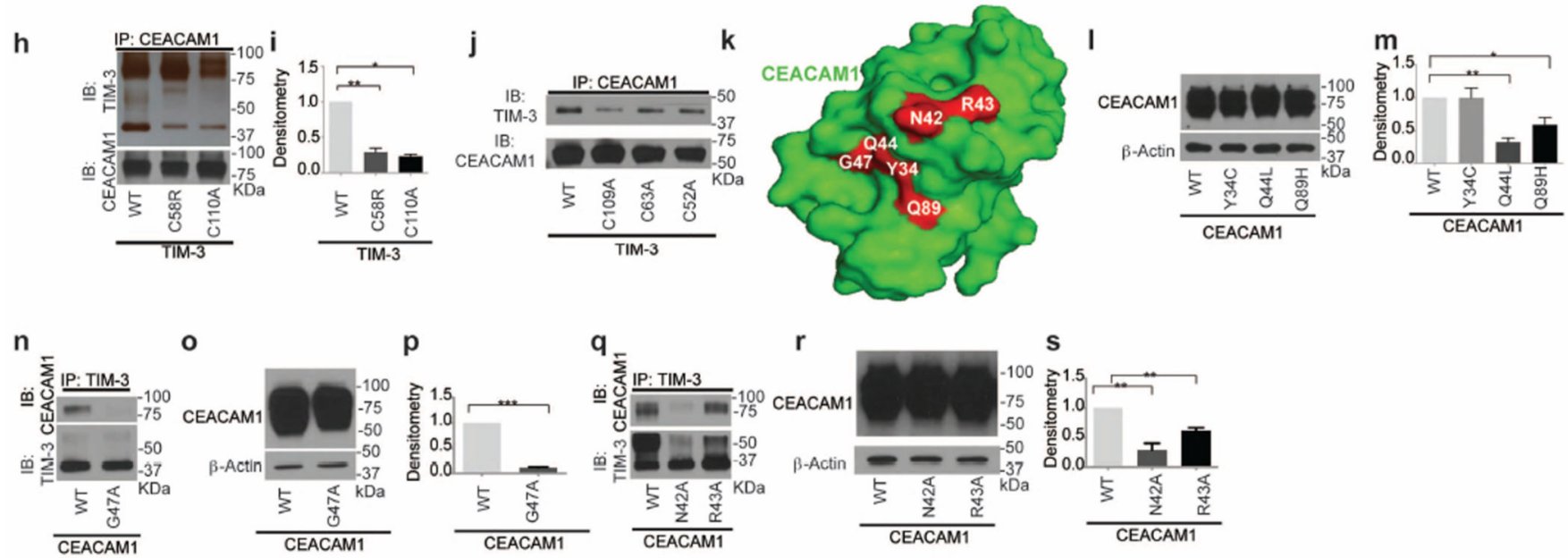

Extended Data Figure 3. Biochemical characterization of interactions between CEACAM1 and TIM-3

a, hTIM-3 does not co-immunoprecipitate (co-IP) with ITGA5 despite interactions with hCEACAM1. HEK293T cells transfected with Flag-ITGA5 and HA-TIM-3 (ITGA5Tw) or Flag-CEACAM1 and HA-TIM-3 (CwTw). Immunoprecipitation with anti-HA antibody and immunoblotted (IB) with anti-Flag antibody are shown. Input represents anti-Flag immunoblot of lysates. b, Co-immunoprecipitation of human TIM-3 and CEACAM1 from activated primary human T cells after $N$-glycanase treatment of lystates followed by immunoprecipitation with anti-human TIM-3 antibodies (2E2, 2E12 or 3F9) or IgG as control and immunoblotted with anti-human CEACAM1 antibody (5F4). Protein lystates from HeLa-CEACAM1 transfectants treated with $N$-glycanase followed by immunoprecipitation with 5F4 and the immune complex used as positive control (pos). c, 
mTIM-3 interacts with mCEACAM1 in mouse T cells. Splenocytes from Ceacam $14 S^{T g}$ Ceacaml $^{-1-}$ and Ceacam1-4L ${ }^{T g}$ Ceacaml $^{-/-}$mice cultured with anti-CD3 $\left(1 \mu \mathrm{g} \mathrm{ml}^{-1}\right)$ or anti-CD3 $\left(1 \mu \mathrm{g} \mathrm{ml}^{-1}\right)$ and anti-CD28 $\left(1 \mu \mathrm{g} \mathrm{ml}^{-1}\right)$ or medium for $96 \mathrm{~h}$. Cell lysates immunoprecipitated with anti-mCEACAM1 antibody (cc1) or with $\mathrm{mIgG}$ and IB with 5D12 (anti-mTIM-3 antibody) are shown. Locations of mTIM-3 protein variants are indicated. $\mathrm{CHO}$, carbohydrate. $\mathbf{d}$, Immunoprecipitation and immunoblot as in a with tunicamycin treated, wild-type HA-hTIM-3 and Flag-hCEACAM1 co-transfected HEK293T cells. Arrowhead denotes core CEACAM1 protein. e, Potential hCEACAM1-interacting residues on hTIM-3 highlighted in blue. f, HEK293 T cells transiently co-transfected with FlaghCEACAM1 and HA-hTIM-3 mutants. Immunoblotting of anti-HA were used to analyse hTIM-3 expression in HEK293T transfectants. Except for Pro50Ala mutation displaying enhanced overall protein expression, all other mutations in the $\operatorname{IgV}$ domain of hTIM-3 are equally detected by anti-HA antibody. g, Quantification of association of hTIM-3 mutants associated with wild-type hCEACAM1 shown in Fig. 2c summing all experiments performed. Association between wild-type hCEACAM1 and hTIM-3 core protein are depicted as reference (set as $1, n=3$, mean \pm s.e.m. shown, unpaired Student's $t$-test). $\mathbf{h}$, Immunoprecipitation with anti-Flag (hCEACAM1) and immunoblot with anti-HA (hTIM-3) or anti-Flag of wild-type hCEACAM1 and mutant hTIM-3 proteins are shown. i, Quantification of $\mathbf{h}$ as performed in $\mathbf{g}$. j, HEK293T cells co-transfected with FlaghCEACAM1 wild-type and HA- hTIM-3 mutants and immunoprecipitation/immunblot as in $\mathbf{h}$ revealing no effects of Cys52Ala or Cys63Ala mutations in hTIM-3 in affecting association with hCEACAM1 in contrast to Cys109Ala mutation of hTIM-3 that disrupts interactions with hCEACAM1. k, Potential hTIM-3-interacting-residues around the FG-CC' cleft of hCEACAM1 highlighted in red. 1, HEK293T cells transiently co-transfected with Flag-hCEACAM1 mutants and wild-type HA-hTIM-3. Immunoblot with anti-Flag antibody was used to analyse hCEACAM1 expression in HEK293T co-transfectants. All hCEACAM1 mutations in IgV domain equally detected. $\mathbf{m}$, Densitometric quantification of $\mathrm{IgV}$ domain hCEACAM1 mutations associating with wild-type HA-hTIM-3 described in Fig. 2d. n-p, Analysis of Gly47Ala mutation of hCEACAM1 in hTIM-3 co-transfected HEK293T cells by immunoprecipitation with anti-HA (hTIM-3) and immunoblot with antiFlag (hCEACAM1) to detect association (n), IB with anti-Flag to confirm similarity of hCEACAM1 transfection (o) and quantification of associated hCEACAM1 of $\mathbf{n}$ as shown in m. q-s, Analysis of hCEACAM1 mutants Asn42Ala and Arg43Ala association with hTIM-3 (q), similarity of transfections ( $\mathbf{r}$ ) and quantification of $\mathbf{q}$ as in $\mathbf{n}-\mathbf{p}$. Representative of four $(\mathbf{d}, \mathbf{h})$, three $(\mathbf{f}, \mathbf{g}, \mathbf{i}, \mathbf{l}-\mathbf{s})$, two $(\mathbf{a}-\mathbf{c})$ and one $(\mathbf{j})$ independent experiments. $* P<0.05 ; * * P<$ $0.01 ; * * * P<.001$. 
a

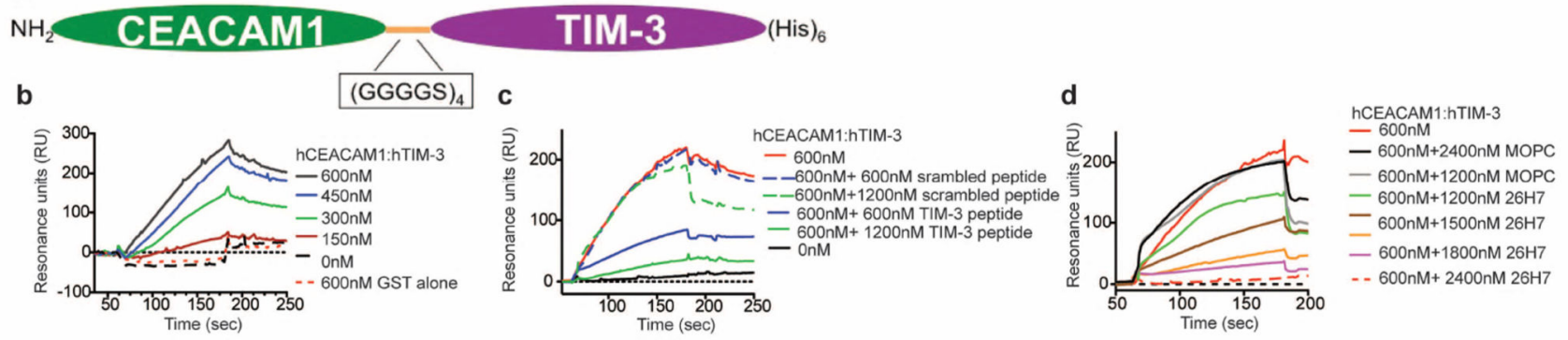

e

g

h
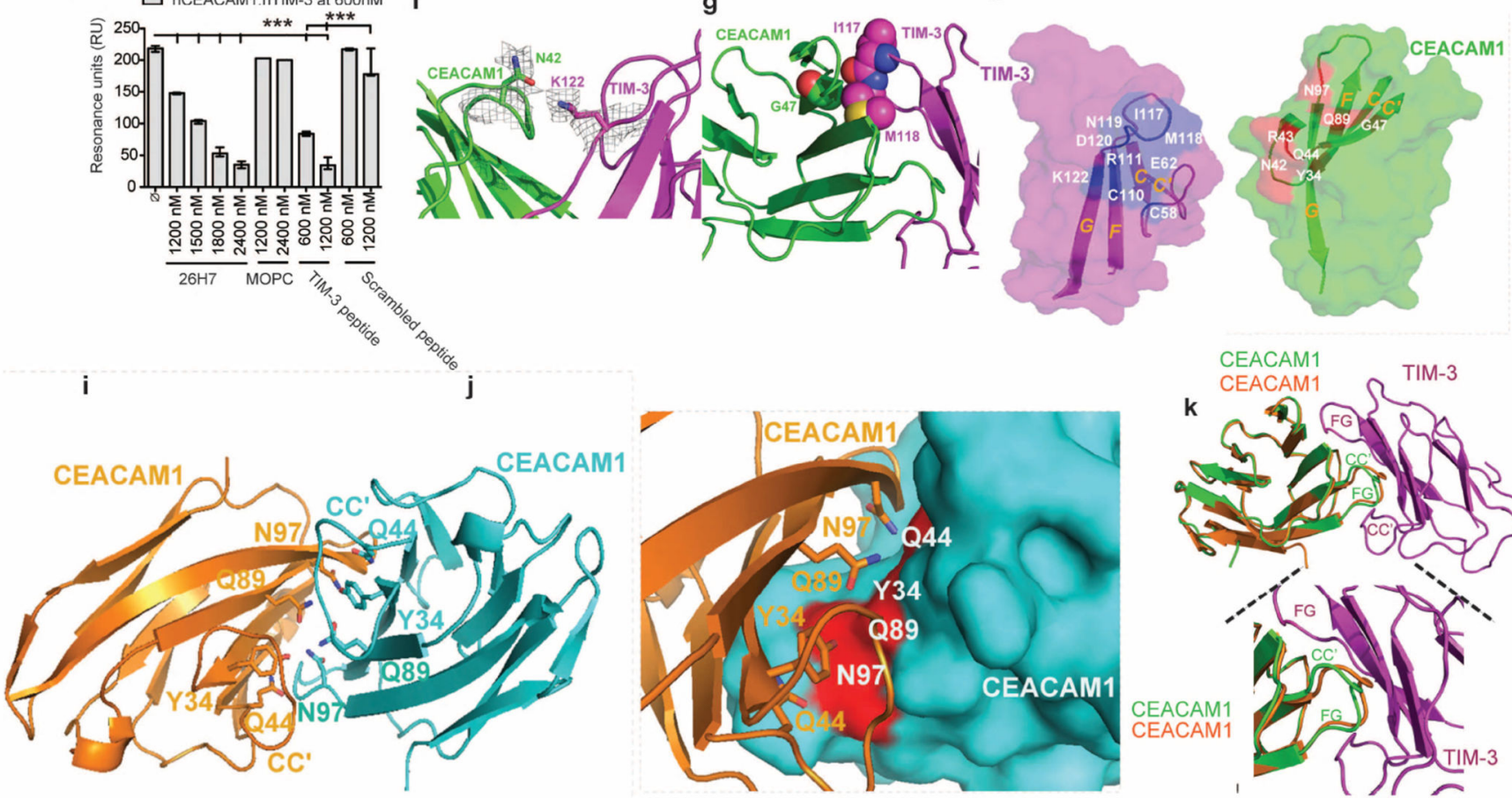

$\left.\left.S^{\text {CEACAM1 } 1}\right)^{1117}\right\}_{\text {TIM- }}^{\text {TIM-3 }}$

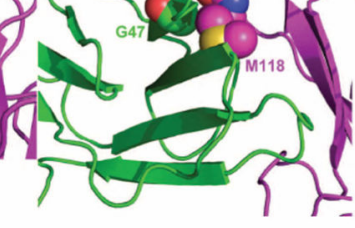

CEACAM1

CEACAM1 TIM-3
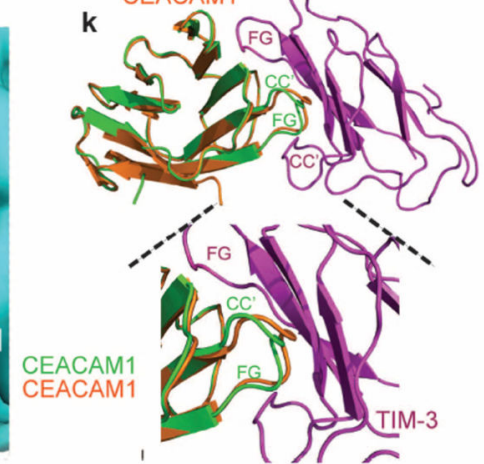

Extended Data Figure 4. Structural analysis of hCEACAM1 and hTIM-3 protein interactions a, Schematic diagram of single-chain construct consisting of hCEACAM1 IgV-domain (amino acids 1-107), a linker consisting of (GGGGS) 4 and hTIM-3 IgV-domain (amino acids 1-105) and C-terminal hexahistidine tag. b-e, Surface plasmon resonance analyses of hCEACAM1-hTIM-3 single-chain interaction with GST-hTIM-3. b, Representative sensorgrams of serial dilutions of hCEACAM1-hTIM-3 single chain flowed over immobilized GST-hTIM-3 or GST alone. c, Representative sensorgrams of 600nM hCEACAM1-hTIM-3 single-chain flowed over immobilized GST-hTIM-3 in presence of various concentrations of blocking hTIM-3 specific peptide (amino acids 58-77) or control scrambled peptide. $\mathbf{d}$, Representative sensorgrams as in $\mathbf{b}$ in presence of various concentrations of anti-hCEACAM1 monoclonal antibody $(26 \mathrm{H} 7)$ or control isotype antibody (mIgG1, MOPC). e, Bar graphs represent resonance units upon equilibrium $\left(\mathrm{RU}_{\mathrm{Eq}}\right)$ of above treatments with mean \pm s.e.m. shown from >three runs. GST-hTIM-3 immobilized by amine coupling. Dilutions of hCEACAM1-hTIM-3 single chain, hCEACAM1-hTIM-3 single chain with either blocking hTIM-3-specific peptide, control scrambled peptide, and $26 \mathrm{H} 7$ antibody or control MOPC antibody were injected over immobilized GST-hTIM-3 at $25^{\circ} \mathrm{C}$. 
Flow rate was $25 \mu \min ^{-1} \mathbf{f}, \mathbf{g}, 2 F_{\mathrm{o}}-2 F_{\mathrm{c}}$ maps contoured at $0.9 \sigma$ showing electron densities for X-ray crystal structure of single chain hCEACAM1-hTIM-3 (PDB code 4QYC). $\mathbf{h}$, Summary of crucial amino acid residues defined biochemically and structurally. i-k, Similarity between apo-hCEACAM1 and hTIM-3-associated CEACAM1. Structure of CEACAM1 homodimer at 2.0 Åresolution (PDB code4QXW) (i).Homophilic 'YQQN' concavity indicated consisting of residues Tyr 34, Gln 44, Gln 89 and Asn97 at hCEACAM1 (IgV)-hCEACAM1 ( $\operatorname{IgV}$ ) interface (j). Superimposition of IgV domain of hCEACAM1 monomer (orange) from $\mathbf{i}$ on hCEACAM1 (green) from hCEACAM1-hTIM-3 heterodimer in Fig. 2e (k). Representative of three $(\mathbf{b}-\mathbf{e})$ independent experiments. ${ }^{* * *} P<$ 0.001 . 


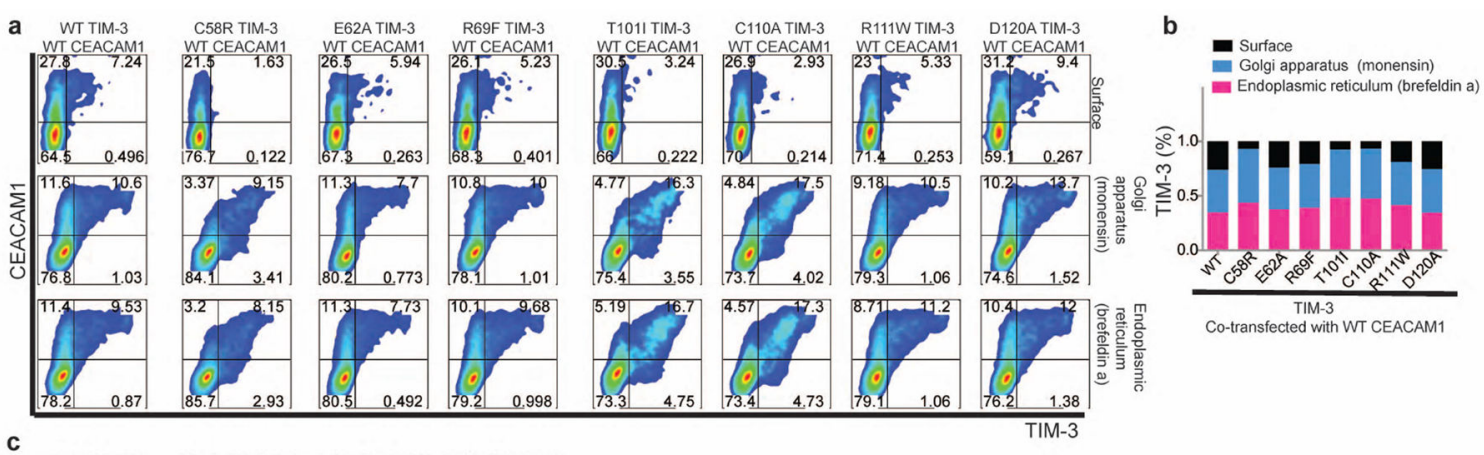

C WT CEACAM1 Y34CCEACAM1 Q44LCEACAM1 Q89HCEACAM1

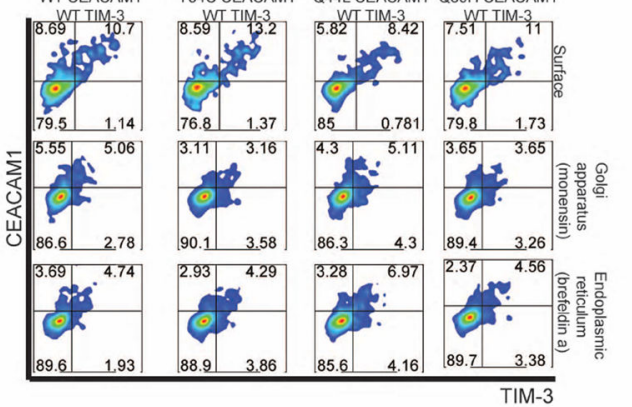

d Surface

-EndoH IB: TIM-3

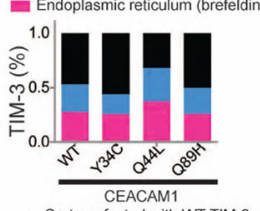

Co-transfected with WT TIM-3

h Th1 cell
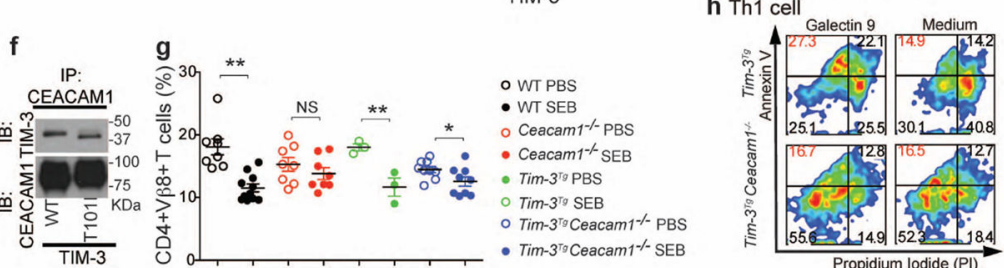

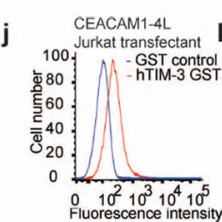

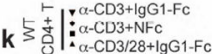

- Tim-3 Ceacam1- SEB

Propidium lodide (PI)
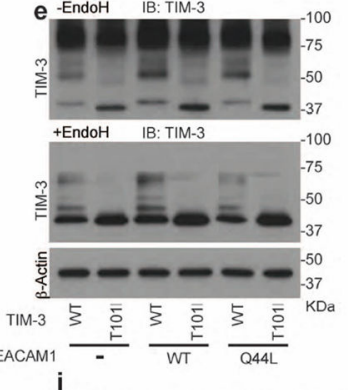

i

GST Protein Pull Down Protocol:

Equilibrate glutathionesepharose column

with bait protein (human GST-TIM-3 I gV protein)

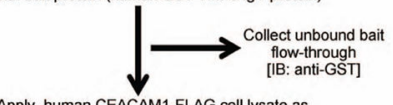

Apply human CEACAM1-FLAG cell lysate as

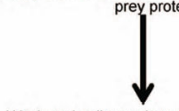

Wash and collect unbound prey flow-through

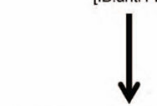

Glutathone elution and collect eluate
[IB: anti-FLAG and anti-GST]

ON-CEACAM1-Fc + mouse lgG1

aN-CEACAM1-FC+ $\alpha$-TIM-3 mAb $(1 \mu \mathrm{g} / \mathrm{ml})$

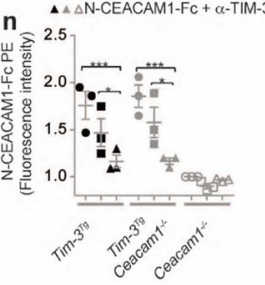

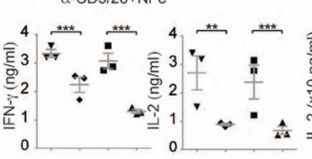

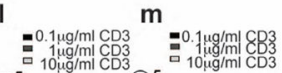

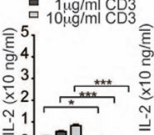

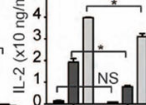
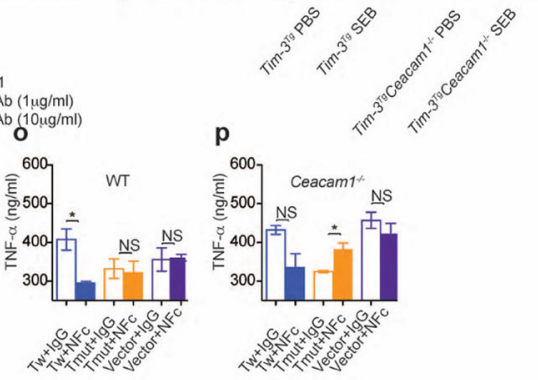

Extended Data Figure 5. CEACAM1 determines TIM-3 expression and function

a, HEK293T cells transiently co-transfected with Flag-hCEACAM1 and wild-type or mutants of HA-hTIM-3. Flow cytometry detecting HA-hTIM-3 (detected with anti-HA) and Flag-hCEACAM1 (detected with 5F4) proteins at cell surface (top), Golgi apparatus (middle) or endoplasmic reticulum (bottom) using monensin and brefeldin A, respectively. b, Cellular distribution of wild-type or mutant hTIM-3 when co-expressed with wild-type hCEACAM1. Total counts of hTIM-3 at surface, Golgi apparatus and endoplasmic reticulum summed up to $100 \%$. Depicted as percentage of hTIM-3. c, HEK293T cells 
transiently co-transfected with wild-type HA-hTIM-3 (detected with 2E2) and wild-type or mutant Flag-hCEACAM1 (detected with anti-Flag). Flow cytometry analyses as in a. d, Cellular distribution of $\mathbf{c}$, as in $\mathbf{b}$. Depicted as percentage of hTIM-3. e, Immunoblot for wild-type or Thr101Ile variant of hTIM-3 showing maturation status in presence of wildtype or mutated (Gln44Leu) hCEACAM1. f, Normal association of Thr101Ile variant of hTIM-3 with hCEACAM1. g, Analysis of $\mathrm{CD} 4^{+} \mathrm{V} \beta 8^{+} \mathrm{T}$ cells after SEB tolerance induction from experimental mice of indicated genotypes. $\mathbf{h}$, Galectin- 9 induction of apoptosis. Annexin $\mathrm{V}^{+}$propidium iodide staining of $\mathrm{T}_{\mathrm{H}} 1$ cells polarized from $\operatorname{Tim} 3^{T g}$ or Tim $3^{T g}$ Ceacam1 ${ }^{-/-}$mice after treatment with galectin- $9\left(2 \mu \mathrm{g} \mathrm{ml}^{-1}\right)$ for $8 \mathrm{~h}$. Note decreased apoptosis in Tim $^{T g}{ }^{T}$ Ceacam1 ${ }^{-/-}$T cells. $\mathbf{i}$, Schematic diagram of protocol used for protein pull-down using in-column IgV domain of GST-hTIM-3 incubated with hCEACAM1 protein derived from transfected HEK293T cells as in Fig. 2m. j, GST or GST-hTIM-3 staining of hCEACAM1-4L-transfected Jurkat T cells. $\mathbf{k}$, Wild-type CD4 ${ }^{+} \mathrm{T}$ cells stimulated with anti-CD3 and/or anti-CD28 in the presence or absence of mCEACAM1 $\mathrm{NFc}$, or IgG1-Fc as control, and cells analysed for secretion of IFN- $\gamma$ and IL-2. 1, m, Characterization of tolerance in SEB model. $\operatorname{Tim} 3^{\operatorname{Tg}}(\mathrm{l})$ and $\operatorname{Tim} 3^{\operatorname{Tg}} \mathrm{Ceacaml}^{-1-}(\mathbf{m})$ mice treated with SEB with schedule described in Extended Data Fig. 1e. Lymph node cells collected after SEB treatment and re-stimulated with soluble anti-CD3 at indicated doses and IL-2 measured by ELISA after $72 \mathrm{~h}$. Note tolerance in $\operatorname{Tim}^{\mathrm{Tg}}$ but not $\operatorname{Tim}^{\mathrm{Tg}}$ Ceacam $1^{-/}$mice. $n=3$ per group. $\mathbf{n}$, Anti-mTIM-3 blockade with $2 \mathrm{C} 12$ antibody of mCEACAM1 NFc or control IgG-Fc staining of $\mathrm{CD}^{+}{ }^{+} \mathrm{T}$ cells from indicated genotypes expressed as levels relative to Ceacam $1^{-1-}$ mice. o, $\mathbf{p}$, Analysis of mTIM-3 cytoplasmic tail function in transmitting mCEACAM1-induced signals. Activated mouse $\mathrm{CD} 4^{+} \mathrm{T}$ cells from wild-type (o) or Ceacaml ${ }^{-1}(\mathbf{p})$ mice were retrovirally transduced, sorted and stimulated with anti-CD3 with either human IgG-Fc (IgG, control) or mCEACAM1 N-terminal domain as NFc and TNF-a secretion assessed by ELISA after $72 \mathrm{~h}$. Note ability of CEACAM1 Nterminal domain to transduce a signal associated with inhibition of TNF-a secretion in wildtype but not Ceacaml ${ }^{-1-}$ T cells. $n=3$ per group. Data are mean \pm s.e.m. and represent three $(\mathbf{f}, \mathbf{g}, \mathbf{k}-\mathbf{p})$ and two $(\mathbf{a}-\mathbf{e}, \mathbf{h}, \mathbf{j})$ independent experiments. ${ }^{*} P<0.05 ; * * P<0.01 ; * * * P<$. 001 . 

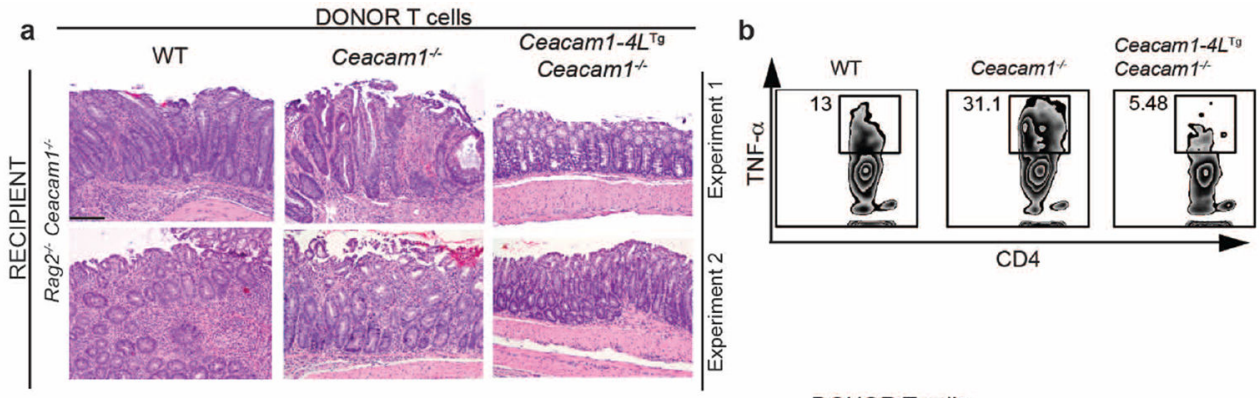

C WT
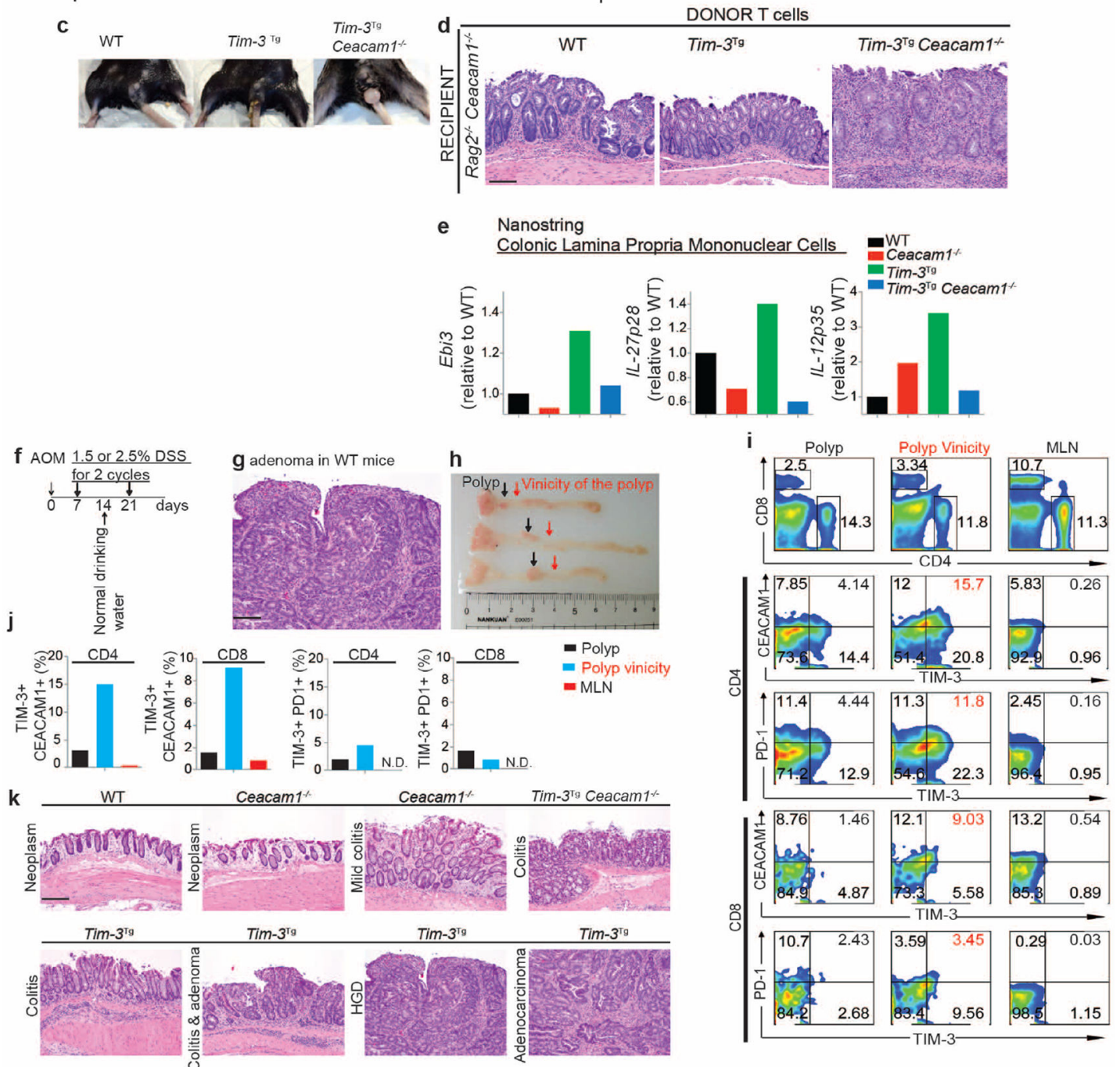

Extended Data Figure 6. CEACAM1 and TIM-3 cooperatively regulate inflammation and antitumour immunity

a, Representative haematoxylin and eosin staining of groups described in Fig. 3e. Scale bar, $50 \mu \mathrm{m}$. b. Flow cytometry for intracellular cytokine assessment of TNF-a expression from infiltrating $\mathrm{CD}^{+} \mathrm{T}$ cells from inflamed colonic lamina propria of $\mathrm{Ceacam1}^{-/-} \mathrm{Rag}^{-/-}$ recipients, 6weeks after transfer with naive $\mathrm{CD} 4^{+} \mathrm{CD} 44^{\text {lo }} \mathrm{CD} 62 \mathrm{~L}^{\text {high }} \mathrm{T}$ cells from indicated genotypes. c, Anorectal prolapse of indicated genotypes. d, Representative haematoxylin and eosin staining of groups described in Fig. 3g. Scale bar, $50 \mu \mathrm{m}$. e, RNA expression 
defined by nanostring of lamina propria mononuclear cells in indicated groups (mean of $n=$ 3 per group). f, Schematic overview of protocol for AOM/DSS colitis-associated cancer model. g, Representative haematoxylin and eosin staining of colon from wild-type mice in AOM/1.5\% DSS model. Scale bar, $50 \mu \mathrm{m} ; \mathbf{h}$, Representative photograph of distal colons of wild-type mice ( $n=3$ per group, anorectal junction at left end) in AOM/1.5\% DSS model. Vertical arrows show the sites for dissection of the polyps (black) and the vicinity of the polyps (red). i, Representative flow cytometry analyses on infiltrating lymphocytes of invading distal colonic polyps or from the vicinity of the polyps or from mesenteric lymph nodes for $\mathrm{CD}^{+}{ }^{+}$and $\mathrm{CD} 8^{+} \mathrm{T}$ cells and expression of CEACAM1 and TIM-3orPD-1 and TIM-3. Note that vicinity of polyps exhibit highest numbers of T cells with an exhausted phenotype. $\mathbf{j}$, Summary of flow cytometry on infiltrating lymphocytes from invading distal colonic polyps or from vicinity of polyps and from mesenteric lymph nodes for $\mathrm{CD} 4^{+}$and CD ${ }^{+}$T cells expressing CEACAM1 and TIM- 3 or PD- 1 and TIM-3 $(n=3$, median shown). $\mathbf{k}$, Representative pathology in AOM/1.5\% DSS model. Scale bar, $60 \mu \mathrm{m}$. HGD, high grade dysplasia. Representative of three independent experiments (a-e, $\mathbf{g}-\mathbf{k})$. 
a Antibody blockade protocol

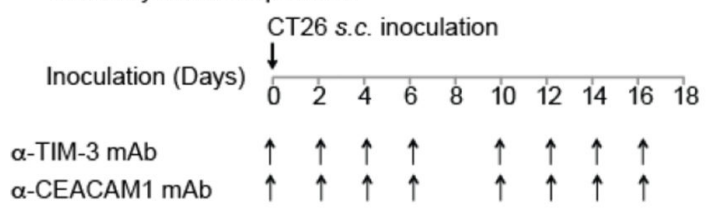

b Antibody blockade protocol
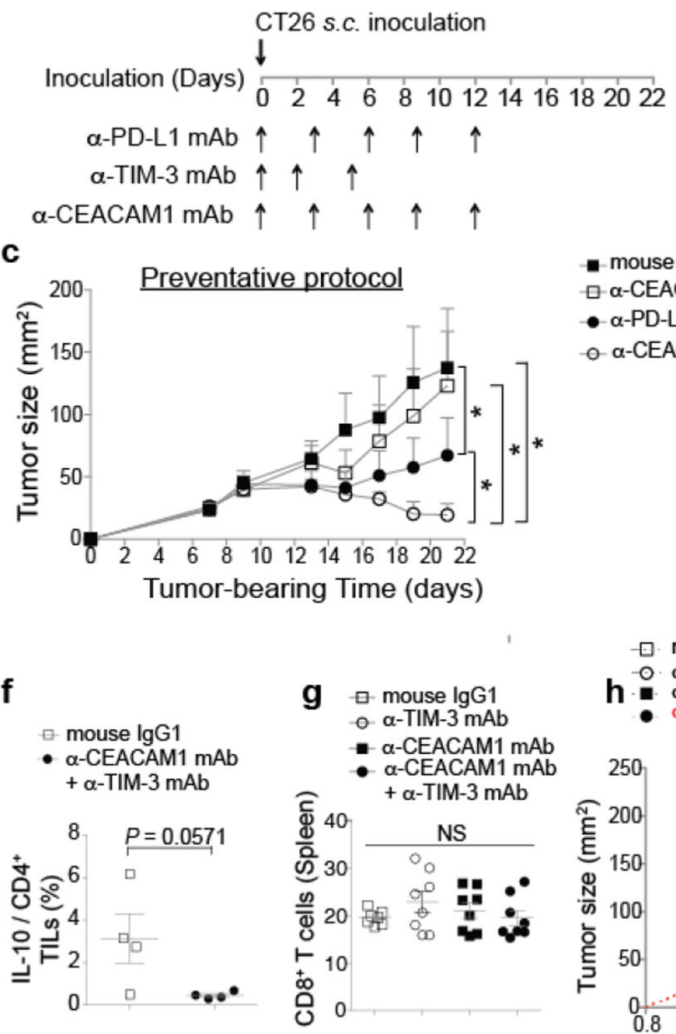

d Antibody blockade protocol

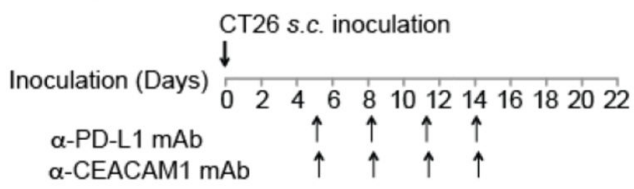

- mouse lgG1 $\square \alpha$-CEACAM1 mAb

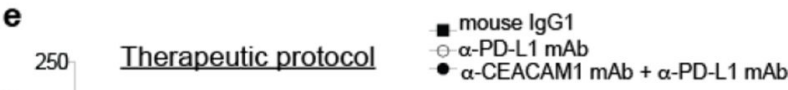

- $\alpha-$ PD-L1 mAb + $\alpha-$ TIM-3 mAb

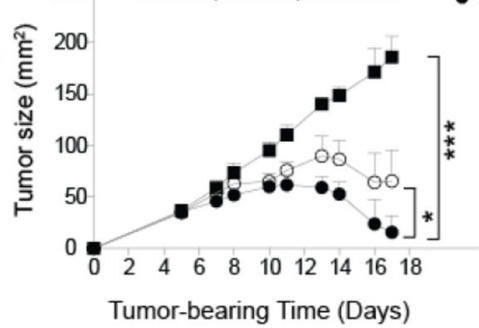

$\square$ mouse lgG1

h. $-\alpha$-TIM-3 mAb $\alpha$-CEACAM1

- $\alpha$-CEACACAM1 mAb $\mathrm{mAb}+\alpha-\mathrm{TIM}-3 \mathrm{mAb}$

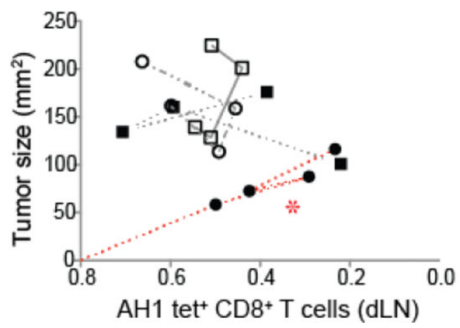

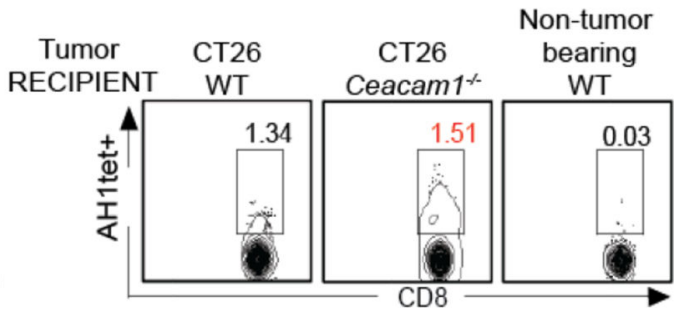

Extended Data Figure 7. Blockade of CEACAM1 and TIM-3 or genetic loss of CEACAM1 increases anti-tumour immunity

a, Schematic presentation of antibody blockade protocol described in Fig. 4g. b, Schematic presentation of antibody blockade protocol referred to in panel c. c, Prevention of CT26 tumour growth with indicated combinations of antibodies as in (b) ( $n=5$ per group, posthoc Dunnett's correction followed by Friedman test). d, Schematic of schedule used for therapeutic antibody administration as described in e. e, Synergy of CEACAM1 and programmed death-ligand1 (PD-L1) blockade in a therapeutic protocol as described in $\mathbf{d}$ was performed in wild-type BALB/c mice that received a subcutaneous inoculation of CT26 tumour cells. Mean tumour size ( $n=5$ per group, with linear regression analysis). Note synergistic increase in anti-tumour effect when CEACAM1 and PD-L1 co-blockade was performed. f, TILs were analysed for the relative proportion of $\mathrm{CD}^{+}{ }^{+} \mathrm{T}$ cells that produced IL-10 as in Fig. 4g ( $n=4$, unpaired Student's $t$-test with Mann-Whitney $U$ correction). g, Percentages of $\mathrm{CD}^{+} \mathrm{T}$ cells from spleen show that antibody treatments have no effects on total CD8 ${ }^{+} \mathrm{T}$ cell numbers $(n=7 / 8$, unpaired two-tailed $t$-test). $\mathbf{h}$, Negative correlation of 
the numbers of $\mathrm{AH} 1$ tet $^{+} \mathrm{CD} 8^{+} \mathrm{T}$ cells and the size of tumours in the draining lymph nodes from the tumour-bearing mice in Fig. 4g (Pearson's correlation coefficient, $r=0.9560, P=$ 0.044). i, Representative flow cytometry for tumour-specific (AH1-tetramer, tet ${ }^{+}$) CD8 ${ }^{+} \mathrm{T}$ cells in draining lymph nodes of mice from the indicated genotypes. Data are mean \pm s.e.m. and represent three (f-i), two (e) and one (c) independent experiments. $* P<0.05 ; * * * P<$ 0.001 .

\section{Extended Data Table 1}

Primers for site-directed mutagenesis of hTIM-3 and hCEACAM1

\begin{tabular}{|c|c|c|c|c|}
\hline \multicolumn{5}{|c|}{ Extended Data Table 1a. TIM-3 mutant primers for site-directed mutagenesis } \\
\hline No. & Mutant N & ame & Forward primer sequence & Reverse primer sequence \\
\hline 1 & $\mathrm{P} 50 \mathrm{~A}$ & & gggaacctcgtggccgtctgctggg & cccagcagacggccacgaggttccc \\
\hline 2 & $\mathrm{C} 52 \mathrm{~A}$ & & cctcgtgccegtcgcctggggcaaagga & tcctttgccccaggcgacgggcacgagg \\
\hline 3 & $\mathrm{C} 58 \mathrm{R}^{*}$ & (rs201750016) & tggggcaaaggagcccgtcctgtgtttgaatg & cattcaaacacaggacgggetcctttgcccca \\
\hline 4 & E62A & & gcctgtcctgtgtttgcatgtggcaacgtggtg & caccacgttgccacatgcaaacacaggacaggc \\
\hline 5 & C63A & & gcaccacgttgccagcttcaaacacaggacaggct & agcctgtcctgtgtttgaagctggcaacgtggtgc \\
\hline 6 & $\mathrm{R} 69 \mathrm{~A}$ & & gtggcaacgtggtgctcgcgactgatgaaagggats & catccetttcatcagtcgcgagcaccacgttgccac \\
\hline 7 & ${\mathrm{~T} 101 I^{*}}^{*}$ & $(\mathrm{rs} 147827860)$ & gtccetgaccatagagaatgtgattctagcagacag & ctgtctgctagaatcacattctctatggtcagggac \\
\hline 8 & C109A & & ggatttggatccggcaggcgtagatcccactgtctg & cagacagtgggatctacgectgccggatccaaatcc \\
\hline 9 & C110A & & cagtgggatctactgcgcccggatccaaatccca & tgggatttggatccgggcgcagtagatcccactg \\
\hline 10 & $\mathrm{R} 111 \mathrm{~W}^{*}$ & (rs145478313) & gggatctactgctgctggatccaaatcccag & ctgggatttggatccagcagcagtagatccc \\
\hline 11 & D120A & & tccaaatcccaggcataatgaatgctgaaaaatttaacctgaagtt & aacttcaggttaaatttttcagcattcattatgcctgggatttgg \\
\hline
\end{tabular}

b. CEACAM1 mutant primers for site directed mutagenesis

\begin{tabular}{lllll} 
No. & Mutant name & Forward primer sequence & Reverse primer sequence \\
\hline 1 & Y34C & $($ rs 147100915) & tttggctacagctggtgcaaaggggaaagagtgg & ccactctttccctttgcaccagctgtagccaaaa \\
2 & N42A & & aggggaaagagtggatggcgcccgtcaaattgtaggatat & atatcctacaatttgacgggcgccatccactctttcccct \\
3 & R43A & ggaaagagtggatggcaacgctcaaattgtaggatatgca & tgcatatcctacaatttgagcgttgccatccactctttcc \\
4 & Q44L & $($ rs 200708090) & gagtggatggcaaccgtctaattgtaggatatgcaata & tattgcatatcctacaattagacggttgccatccactc \\
5 & G47A & & ggcaaccgtcaaattgtagcatatgcaataggaactcaa & ttgagttcctattgcatatgctacaatttgacggttgcc \\
6 & Q89H $^{*}$ & (rs8111468) & caggattctacaccctacatgtcataagtcagatcttg & caagatctgactttatgacatgtagggtgtagaatcctg \\
\hline
\end{tabular}

a, hTIM-3 primers, b, hCEACAM1 primers. Mutations were chosen on the basis of orthologous human residues reported previously 13 in mTIM-3 as involved in non-galectin-9 interactions with an unknown ligand (hTIM-3 residues 1,4,6,10 and 11 in a); orthologous human residues in hCEACAM1 (hCEACAM1 residues 1,4, 5 and 6 in b) predicted to be involved in mTIM-3 interactions on the basis of studies described in Extended Data Fig. $2 \mathrm{~g}$ and Supplementary Information; natural allelic variants of amino acid residues in hTIM-3 (residues 3, 7 and 10 in a) and hCEACAM1 (1, 4 and 6 in b) described above or others (hTIM-3 residue 7 in a), which were extracted from human exomic databases. Amino acid residues predicted to be involved in hTIM-3 (IgV)-hCEACAM1 (IgV) interactions on the basis of X-ray crystallographic structural models (hCEACAM1 residues 2 and 3 in b) as described in Supplementary Information, and cysteine residues involved in intrachain disulphide bonds adjacent to the CC' and FG loops of hTIM-3 (Cys 58-Cys 109, Cys52-Cys63 and Cys3S-Cys 110) as described in Supplementary Information.

Asterisks represent annotated human natural single nucleotide polymorphisms. 


\section{Extended Data Table 2}

Crystal Information, data collection and refinement parameters

\begin{tabular}{|c|c|c|}
\hline & hCEACAM1:hTIM-3 single chain & CEACAM1 (Ig-V) \\
\hline \multicolumn{3}{|c|}{ Data collection statistics } \\
\hline Space Group & $\mathrm{P} 4{ }_{1} 2_{1} 2$ & $\mathrm{P} 42_{1} 2$ \\
\hline Cell Dimensions $(\AA)$ & $75.76,75.76,147.40$ & $107.16,107.16,61.60$ \\
\hline Resolution $(\AA)^{*}$ & $36.85-3.40(3.72-3.40)$ & $47.92-2.04(2.11-2.03)$ \\
\hline No. of measurements & 65773 & 219575 \\
\hline Unique reflections & 6397 & 23421 \\
\hline I/sigma I & $10.2(6.5)$ & $8.8(2.3)$ \\
\hline Completeness (\%) & $99.9(100)$ & $99.9(100)$ \\
\hline Redundancy & $10.3(10.1)$ & $9.4(9.0)$ \\
\hline$R_{\text {merge }}(\%)$ & $24.5(49.9)$ & $18.9(98.4)$ \\
\hline \multicolumn{3}{|l|}{ Structure refinement } \\
\hline$R_{\text {work }}(\%)$ & 34.5 & 20.3 \\
\hline$R_{\text {free }}(\%)$ & 37.3 & 24.2 \\
\hline \multicolumn{3}{|l|}{ R.m.s deviations } \\
\hline Bond lengths $(\AA)$ & 0.014 & 0.014 \\
\hline Bond angles $\left({ }^{\circ}\right)$ & 1.99 & 1.23 \\
\hline \multicolumn{3}{|l|}{ No. atoms } \\
\hline Protein & 3127 & 1680 \\
\hline Ligand & & 47 \\
\hline Water & 19 & 66 \\
\hline \multicolumn{3}{|l|}{ B Factors } \\
\hline Protein & 21.20 & 23.30 \\
\hline Ligand & & 38.40 \\
\hline Water & 30.0 & 28.60 \\
\hline PDB ID & 4QYC & $4 \mathrm{QXW}$ \\
\hline
\end{tabular}

Extended Data Table 3

Genotype analysis for human TIM3 alleles in Inflammatory bowel disease

\begin{tabular}{lcc} 
a. Study numbers & & \\
Source & $\begin{array}{c}\text { Number of } \\
\text { individuals }\end{array}$ & Genoytpe distribution \\
\hline German IBD patients & 5,598 & $\mathrm{AA}=3 / \mathrm{AG}=77 / \mathrm{GG}=5,518$ \\
German CD patients & 3,975 & $\mathrm{AA}=2 / \mathrm{AG}=54 / \mathrm{GG}=3,919$ \\
German UC patients & 1,623 & $\mathrm{AA}=1 / \mathrm{AG}=23 / \mathrm{GG}=1,599$ \\
German healthy controls & 3,928 & $\mathrm{AA}=0 / \mathrm{AG}=50 / \mathrm{GG}=3,878$ \\
EVS, European Americans & 4,300 & $\mathrm{AA}=0 / \mathrm{AG}=36 / \mathrm{GG}=4,264$ \\
\hline
\end{tabular}

Nature. Author manuscript; available in PMC 2015 January 17. 
b. Studied TIM3 SNPs

\begin{tabular}{|c|c|c|c|c|c|c|c|c|c|c|c|c|}
\hline \multirow[b]{2}{*}{ rs-number } & \multicolumn{3}{|c|}{ CD patients } & \multicolumn{3}{|c|}{ UC patients } & \multicolumn{3}{|c|}{ IBD patients } & \multicolumn{3}{|c|}{ Healthy controls } \\
\hline & $\mathbf{A A}$ & $\mathbf{A B}$ & BB & $\mathbf{A A}$ & $\mathbf{A B}$ & BB & $\mathbf{A A}$ & $\mathbf{A B}$ & BB & $\mathbf{A A}$ & $\mathbf{A B}$ & BB \\
\hline rs201054625 & 2329 & 0 & 0 & 1448 & 0 & 0 & 3777 & 0 & 0 & 2913 & 0 & 0 \\
\hline rs 145478313 & 2302 & 2 & 0 & 1445 & 0 & 0 & 3747 & 2 & 0 & 2875 & 3 & 0 \\
\hline rs190484372 & 2318 & 0 & 0 & 1439 & 0 & 0 & 3757 & 0 & 0 & 2894 & 0 & 0 \\
\hline rs 147827860 & 2284 & 42 & 2 & 1423 & 22 & 1 & 3707 & 64 & 3 & 2879 & 32 & 0 \\
\hline rs35960726 & 2305 & 24 & 0 & 1425 & 22 & 0 & 3730 & 46 & 0 & 2861 & 51 & 0 \\
\hline rs181855375 & 2308 & 0 & 0 & 1442 & 0 & 0 & 3750 & 0 & 0 & 2896 & 0 & 0 \\
\hline rs184868814 & 2328 & 1 & 0 & 1447 & 0 & 0 & 3775 & 1 & 0 & 2912 & 1 & 0 \\
\hline rs201750016 & 2275 & 0 & 0 & 1433 & 0 & 0 & 3708 & 0 & 0 & 2839 & 0 & 0 \\
\hline rs41283181 & 2314 & 1 & 0 & 1444 & 0 & 0 & 3758 & 1 & 0 & 2894 & 0 & 0 \\
\hline rs 147605860 & 2329 & 0 & 0 & 1447 & 0 & 0 & 3776 & 0 & 0 & 2913 & 0 & 0 \\
\hline rs 142180056 & 2329 & 0 & 0 & 1448 & 0 & 0 & 3777 & 0 & 0 & 2913 & 0 & 0 \\
\hline
\end{tabular}

c. Clinical data

\begin{tabular}{|c|c|c|c|}
\hline \multirow{2}{*}{ Clinical information } & \multicolumn{3}{|c|}{ Patient } \\
\hline & 1 & 2 & 3 \\
\hline Diagnosis & $\mathrm{CD}$ & $\mathrm{CD}$ & $\mathrm{UC}$ \\
\hline Sex & male & female & male \\
\hline Age of onset & 33 & 13 & 40 \\
\hline Disease localisation & Colon & Ileum, colon, rectum & Colon \\
\hline Disease characteristics & $\begin{array}{l}\text { Entero-cutaneous fistula and } \\
\text { colonic stenosis }\end{array}$ & $\begin{array}{l}\text { Snail-track ulcers, anal stenosis, } \\
\text { granulomas, perianal abscesses } \\
\text { and fistulas }\end{array}$ & Perianal fistula \\
\hline Extraintestinal manifestations & Pancreatitis & Eye, joints, skin & Skin \\
\hline Treatment & Azathioprine, ASA, steroids & Azathioprine, corticosteroids & unknown \\
\hline Surgery & $\begin{array}{l}\text { Colostomy at age } 44 \text {, two large } \\
\text { bowel surgeries in the } \\
\text { following } 3 \text { years }\end{array}$ & Surgery at ages 19 and 21 & unknown \\
\hline Other & $\begin{array}{l}\text { Iron and selenium deficincy, } \\
\text { hyperuricemia, depression }\end{array}$ & $\begin{array}{c}\text { Chronic active CD, refractory } \\
\text { to immunosuppression, } \\
\text { hypertension }\end{array}$ & $\begin{array}{c}\text { Family history } \\
\text { of IBD }\end{array}$ \\
\hline
\end{tabular}

a, Number of successfully genotyped German patients and controls and corresponding distribution of genotypes for the Thr101Ile missense variant in TIM3, including the genotype distribution in individuals of European descent (European Americans) downloaded from the Exome Variant Server (EVS), NHLBI GO Exome Sequencing Project (http:// evs.gs.washington.edu/EVS/). Genotyping 11 rare variants in TIM3, in a cohort of 5,634 inflammatory bowel disease and 3,940 control subjects, we observed homozygous rs147827860 (Thr101Ile) carriage exclusively in three IBD subjects (2 Crohn's disease (CD) and 1 ulcerative colitis (UC)), but no control subjects which significantly deviated from HardyWeinberg equilibrium in IBD cases $(P=0.0033)$ but not controls $(P=1.00)$. b. Description of TIM3 single nucleotide polymorphisms (SNPs) analysed in cohorts described in a. c, Clinical data for the three patients found to be homozygous for the rs147827860 (Thr101Ile) variant.

\section{Supplementary Material}

Refer to Web version on PubMed Central for supplementary material. 


\section{Acknowledgements}

We thank T. Gallagher, M. Yoshida and K. Holmes for essential reagents, R. Gali for statistical assistance, C. Chen, T. Wesse, S. Sabet, S. Greve, T. Henke, D. Tan, K. Sakuishi and J. Sullivan for technical assistance, E. Greenfield and C. Bencsics for core services, and J. H. Wang, E. Reinherz, R. Grenha, H. lijima, J. Shively, A. Kaser, T. E. Adolph, K. Baker, D. Ringeand S. Zeissig for discussions. We thank the staff of the Dana Farber/Harvard Cancer Center monoclonal antibody core for purification of proteins used in X-ray crystallography and beam lineX25 and X6A of the National Synchrotron Light Source (NSLS), Brookhaven National Laboratory, USA. The NSLS is supported by the US Department of Energy. This work was supported by the American Cancer Society grant RSG-11-057-01-LIB (ACA); the Norwegian PSC research center and the Unger Vetlesen Medical Fund (E.M.); Crohn's \& Colitis Foundation of America fellowship grant (Y.-H.H.); Deutsche Forschungsgemeinschaft (DFG) Cluster of Excellence 'Inflammation at Interfaces' Award (A.F. and B.-S.P.); Harvard Clinical Translational Science Center, UL1 TR001102 (R. Gali); the National Basic Research Program of China No. 2010CB529906 (Q.C.); Canadian Institute of Health Research (K.L.C. and N.B.); Canadian Institute of Health Research grant MOP-93787 (M.A.O.); AACR-Pancreatic Cancer Action Network (H.L.P. and S.K.D.); National Institutes of Health (NIH) grant GM32415 (G.A.P.); NIH grants AI073748, NS045937, AI039671 and AI056299 (V.K.K.); NIH grants DK044319, DK051362, DK053056, DK088199, the Harvard Digestive Diseases Center (HDDC) DK0034854 and High Point Foundation (R.S.B.).

\section{References}

1. Monney L, et al. Th1-specific cell surface protein Tim-3 regulates macrophage activation and severity of an autoimmune disease. Nature. 2002; 415:536-541. [PubMed: 11823861]

2. Sabatos CA, et al. Interaction of Tim-3 and Tim-3 ligand regulates T helper type 1 responses and induction of peripheral tolerance. Nature Immunol. 2003; 4:1102-1110. [PubMed: 14556006]

3. Sánchez-Fueyo A, et al. Tim-3 inhibits T helper type 1-mediated auto-and alloimmune responses and promotes immunological tolerance. Nature Immunol. 2003; 4:1093-1101. [PubMed: 14556005]

4. Jones RB, et al. Tim-3 expression defines a novel population of dysfunctional T cells with highly elevated frequencies in progressive HIV-1 infection. J. Exp. Med. 2008; 205:2763-2779. [PubMed: 19001139]

5. Sakuishi K, et al. Targeting Tim-3 and PD-1 pathways to reverse T cell exhaustion and restore antitumor immunity. J. Exp. Med. 2010; 207:2187-2194. [PubMed: 20819927]

6. Nagaishi T, et al. SHP1 phosphatase-dependent T cell inhibition by CEACAM1 adhesion molecule isoforms. Immunity. 2006; 25:769-781. [PubMed: 17081782]

7. Gray-Owen SD, Blumberg RS. CEACAM1: contact-dependent control of immunity. Nature Rev. Immunol. 2006; 6:433-146. [PubMed: 16724098]

8. lijima H. Specific regulation of T helper cell 1-mediated murine colitis by CEACAM1. J. Exp. Med. 2004; 199:471-482. [PubMed: 14970176]

9. Boulton IC, Gray-Owen SD. Neisserial binding to CEACAM1 arrests the activation and proliferation of $\mathrm{CD}^{+} \mathrm{T}$ lymphocytes. Nature Immunol. 2002; 3:229-236. [PubMed: 11850628]

10. Chen L, et al. The short isoform of the CEACAM1 receptorin intestinal t cells regulates mucosal immunity and homeostasis via Tfh cell induction. Immunity. 2012; 37:930-946. [PubMed: 23123061]

11. Kearney ER, Pape KA, Joh DY, Jenkins MK. Visualization of peptide-specific T cell immunity and peripheral tolerance induction in vivo . Immunity. 1994; 1:327-339. [PubMed: 7889419]

12. Soderberg O, et al. Direct observation of individual endogenous protein complexes in situ by proximity ligation. Nature Methods. 2006; 3:995-1000. [PubMed: 17072308]

13. Cao E, et al. T cell immunoglobulin mucin-3 crystal structure reveals a galectin-9-independent ligand-binding surface. Immunity. 2007; 26:311-321. [PubMed: 17363302]

14. Tan K, et al. Crystal structure of murine sCEACAM1a[1,4]: a coronavirus receptor in the CEA family. EMBO J. 2002; 21:2076-2086. [PubMed: 11980704]

15. Zhu C, et al. The Tim-3 ligand galectin-9 negatively regulates T helper type 1 immunity. Nature Immunol. 2005; 6:1245-1252. [PubMed: 16286920]

16. Dardalhon V, et al. Tim-3/galectin-9 pathway: regulation of Th1 immunity through promotion of CD11b ${ }^{+}$Ly-6G ${ }^{+}$myeloid cells. J. Immunol. 2010; 185:1383-1392. [PubMed: 20574007] 
17. Rangachari M, et al. Bat3 promotes T cell responses and autoimmunity by repressing Tim-3mediated cell death and exhaustion. Nature Med. 2012; 18:1394-1400. [PubMed: 22863785]

18. Lee J, et al. Phosphotyrosine-dependent coupling of Tim-3 to T-cell receptor signaling pathways. Mol. Cell. Biol. 2011; 31:3963-3974. [PubMed: 21807895]

19. Barber DL, et al. Restoring function in exhausted CD8 T cells during chronic viral infection. Nature Cell Biol. 2006; 439:682-687.

20. Hirahara K, et al. Interleukin-27 priming of T cells controls IL-17 production in trans via induction of the ligand PD-L1. Immunity. 2012; 36:1017-1030. [PubMed: 22726954]

21. Collison LW, et al. The inhibitory cytokine IL-35 contributes to regulatory T-cell function. Nature. 2007; 450:566-569. [PubMed: 18033300]

22. Fridman WH, Pagès F, Sautès-Fridman C, Galon J. The immune contexture in human tumours: impact on clinical outcome. Nature Rev. Cancer. 2012; 12:298-306. [PubMed: 22419253]

23. Huang AY, et al. The immunodominant major histocompatibility complex class l-restricted antigen of a murine colon tumor derives from an endogenous retroviral gene product. Proc. Natl Acad. Sci. USA. 1996; 93:9730-9735. [PubMed: 8790399]

24. Leung $\mathrm{N}$, et al. Deletion of the carcinoembryonic antigen-related cell adhesion molecule 1 (Ceacam1) gene contributes to colon tumor progression in a murine model of carcinogenesis. Oncogene. 2006; 25:5527-5536. [PubMed: 16619040]

25. Bansal-Pakala P, Jember AG, Croft M. Signaling through OX40 (CD134) breaks peripheral T-cell tolerance. Nature Med. 2001; 7:907-912. [PubMed: 11479622]

26. Jeon M-S, et al. Essential role of the E3 ubiquitin ligase Cbl-b in T cell anergy induction. Immunity. 2004; 21:167-177. [PubMed: 15308098]

27. Moon JJ, et al. Tracking epitope-specific T cells. Nature Protocols. 2009; 4:565-581.

28. Chen C-J, Shively JE. The cell-cell adhesion molecule carcinoembryonic antigen-related cellular adhesion molecule 1 inhibits IL-2 production and proliferation in human T cells by association with Src homology protein-1 and down-regulates IL-2 receptor. J. Immunol. 2004; 172:35443552. [PubMed: 15004155]

29. Patel PC, et al. Inside-out signaling promotes dynamic changes in the carcinoembryonic antigenrelated cellular adhesion molecule 1 (CEACAM1) oligomeric state to control its cell adhesion properties. J. Biol. Chem. 2013; 288:29654-29669. [PubMed: 24005674]

30. Smith AL, et al. Monoclonal antibody to the receptor for murine coronavirus MHV-A59 inhibits viral replication in vivo. J. Infect. Dis. 1991; 163:879-882. [PubMed: 1849166]

31. Gallagher TM. A role for naturally occurring variation of the murine coronavirus spike protein in stabilizing association with the cellular receptor. J. Virol. 1997; 71:3129-3137. [PubMed: 9060676]

32. Morales VM, et al. Regulation of human intestinal intraepithelial lymphocyte cytolytic function by biliary glycoprotein (CD66a). J. Immunol. 1999; 163:1363-1370. [PubMed: 10415036]

33. Watt SM. Homophilic adhesion of human CEACAM1 involves N-terminal domain interactions: structural analysis of the binding site. Blood. 2001; 98:1469-1479. [PubMed: 11520797]

34. Chen D, et al. Carcinoembryonic antigen-related cellular adhesion molecule 1 isoforms alternatively inhibit and costimulate human T cell function. J. Immunol. 2004; 172:3535-3543. [PubMed: 15004154]

35. Hastings WD, et al. TIM-3 is expressed on activated human CD4+ T cells and regulates Th1 and Th17 cytokines. Eur. J. Immunol. 2009; 39:2492-2501. [PubMed: 19676072]

36. Pertel T, et al. TRIM5 is an innate immune sensor for the retrovirus capsid lattice. Nature. 2011; 472:361-365. [PubMed: 21512573]

37. Holst J, Vignali KM, Burton AR, Vignali DAA. Rapid analysis of T-cell selection in vivo using T cell-receptor retrogenic mice. Nature Methods. 2006; 3:191-197. [PubMed: 16489336]

38. Persons DA, et al. Retroviral-mediated transfer of the green fluorescent protein gene into murine hematopoietic cells facilitates scoring and selection of transduced progenitors in vitro and identification of genetically modified cells in vivo. Blood. 1997; 90:1777-1786. [PubMed: 9292510] 
39. Zhang X, Schwartz J-CD, Almo SC, Nathenson SG. Expression, refolding, purification, molecular characterization, crystallization, and preliminary X-ray analysis of the receptor binding domain of human B7-2. Protein Expr. Purif. 2002; 25:105-113. [PubMed: 12071705]

40. Battye TGG, Kontogiannis L, Johnson O, Powell HR, Leslie AGW. iMOSFLM: a new graphical interface for diffraction-image processing with MOSFLM. Acta Crystallogr. D. 2011; 67:271-281. [PubMed: 21460445]

41. Winn MD, et al. Overview of the CCP4 suite and current developments. Acta Crystallogr. D. 2011; 67:235-242. [PubMed: 21460441]

42. Adams PD, et al. PHENIX: a comprehensive Python-based system for macromolecular structure solution. Acta Crystallogr. D. 2010; 66:213-221. [PubMed: 20124702]

43. Emsley P, Cowtan K. Coot: model-building tools for molecular graphics. Acta Crystallogr. D. 2004; 60:2126-2132. [PubMed: 15572765]

44. Mizuguchi K, Go N. Seeking significance in three-dimensional protein structure comparisons. Curr. Opin. Struct. Biol. 1995; 5:377-382. [PubMed: 7583636]

45. Thompson JD, Gibson TJ, Higgins DG. Multiple sequence alignment using ClustalW and ClustalX. Chapter 2. Unit 2.3. Curr. Protoc. Bioinformatics. 2002

46. Lyskov S, Gray JJ. The RosettaDock server for local protein-protein docking. Nucleic Acids Res. 2008; 36:W233-W238. [PubMed: 18442991]

47. Kaufmann KW, Lemmon GH, DeLuca SL, Sheehan JH, Meiler J. Practically useful: what the ROSETTA protein modeling suite can do for you. Biochemistry. 2010; 49:2987-2998. [PubMed: 20235548]

48. Lennard-Jones JE. Classification of inflammatory bowel disease. Scand. J. Gastroenterol. Suppl. 1989; 170:2-6. [PubMed: 2617184]

49. Truelove SC, Pena AS. Course and prognosis of Crohn's disease. Gut. 1976; 17:192-201. [PubMed: 1269986]

50. Krawczak M, et al. PopGen: population-based recruitment of patients and controls for the analysis of complex genotype-phenotype relationships. Community Genet. 2006; 9:55-61. [PubMed: 16490960]

51. Barrett JC, Fry B, Maller J, Daly MJ. Haploview: analysis and visualization of LD and haplotype maps. Bioinformatics. 2005; 21:263-265. [PubMed: 15297300]

52. Ye K, et al. Phospholipase $\mathrm{C} \gamma 1$ is a physiological guanine nucleotide exchange factor for the nuclear GTPase PIKE. Nature. 2002; 415:541-544. [PubMed: 11823862]

53. Powrie F, Leach MW, Mauze S, Caddle LB, Coffman RL, et al. Phenotypically distinct subsets of $\mathrm{CD}^{+}{ }^{+} \mathrm{T}$ cells induce or protect from chronic intestinal inflammation in C. B-17 scid mice. Int. Immunol. 1993; 5:1461-1471. [PubMed: 7903159]

54. Okayasu I, Ohkusa T, Kajiura K, Kanno J, Sakamoto S. Promotion of colorectal neoplasia in experimental murine ulcerative colitis. Gut. 1996; 39:87-92. [PubMed: 8881816]

55. Neufert C, Becker C, Neurath MF. An inducible mouse model of colon carcinogenesis for the analysis of sporadic and inflammation-driven tumor progression. Nature Protocols. 2007; 2:19982004.

56. Adolph TE, et al. Paneth cells as a site of origin for intestinal inflammation. Nature. 2013; 503:272-276. [PubMed: 24089213] 
a

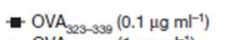

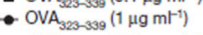

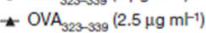

$7-\mathrm{OVA}_{323-309}\left(10 \mu \mathrm{g} \mathrm{m} \mathrm{ml}^{-1}\right)$

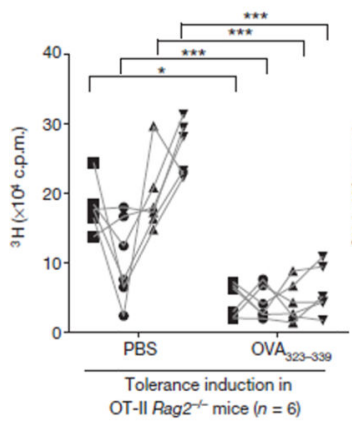

b

- OVA $323-3939\left(0.1 \mu \mathrm{g} \mathrm{m} \mathrm{ml}^{-1}\right)$

- $\mathrm{OVA}_{32-3939}\left(1 \mu \mathrm{g} \mathrm{m}^{-1}\right)$

$+\mathrm{OVA}_{3223939}\left(2.5 \mathrm{\mu g} \mathrm{m}^{-1}\right)$

$\leftarrow \operatorname{OVA}_{323-999}\left(10 \mu \mathrm{gll}^{-1}\right)$

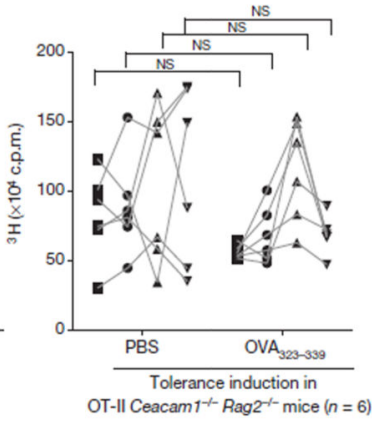

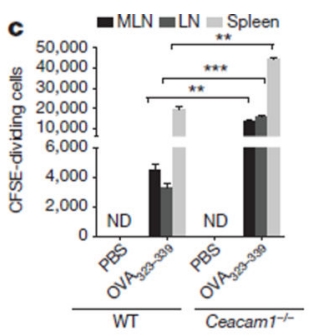
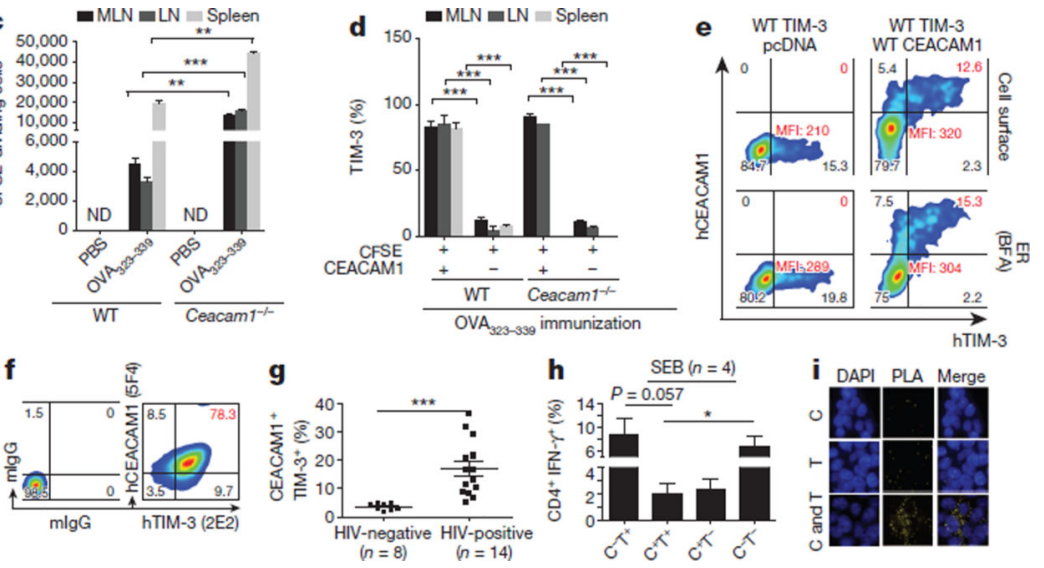

Figure 1. TIM-3 and CEACAM1 are co-expressed on $\mathrm{T}$ cells during induction of tolerance a, b, Tolerance induction in indicated mice. Median c.p.m., counts per minute. c, d, Responses of CFSE-labelled transgenic OT-II Rag $^{-1-}$ T cells in mesenteric lymph nodes (MLN), peripheral lymph node (LN) or spleen of wild-type (WT) or Ceacam1 ${ }^{-/}$recipients to PBS ( $n=3$ per group) or OVA ( $n=5$ per group) for proliferation (c) and CEACAM1 or TIM-3 (d) expression. ND, not detectable. e, hCEACAM1 and hTIM-3 expression in cotransfected HEK293T cells. Percentage and mean fluorescence intensity (MFI) of hTIM-3 indicated. BFA, brefeldin A; ER, endoplasmic reticulum. f, hCEACAM1 and hTIM-3 expression on activated primary $\mathrm{CD}^{+}$human $\mathrm{T}$ cells. $\mathbf{g}, \mathbf{h}, \mathrm{CEACAM} 1^{+} \mathrm{TIM}-3^{+} \mathrm{CD} 4^{+} \mathrm{T}$ cells $(\mathbf{g})$ and intracellular cytokine staining for IFN- $\gamma$ in $\mathrm{CD}^{+} \mathrm{T}$ cells after SEB stimulation (h) in HIV infection. C, CEACAM1; T, TIM-3 ( $n=4$ per group). i, In situ proximity ligation assay of hCEACAM1 and hTIM-3 co-transfected HEK293T as in e. DAPI, 4',6diamidino-2-phenylindole. All data are mean \pm s.e.m. and represent five $(\mathbf{e}, \mathbf{f})$, three $(\mathbf{c}, \mathbf{d}, \mathbf{i})$ and two (a, b) independent experiments. $* P<0.05$; ** $P<0.01$; *** $P<0.001$. 


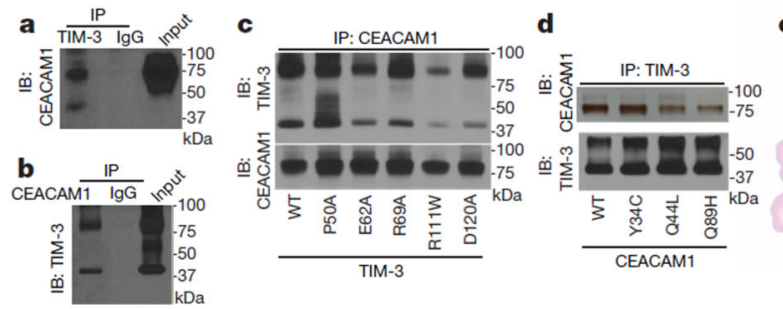

h

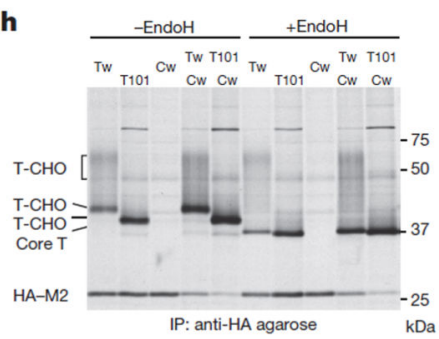

m

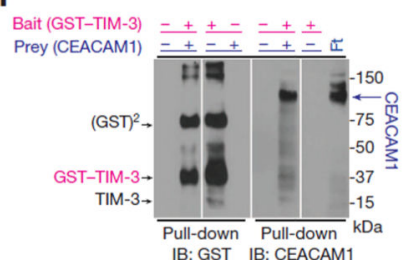

i

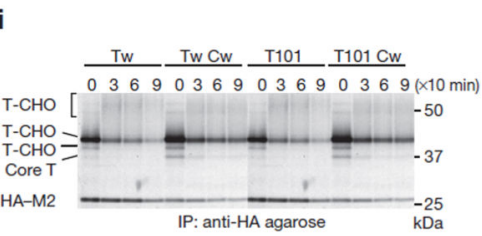

n

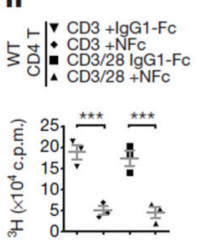

o
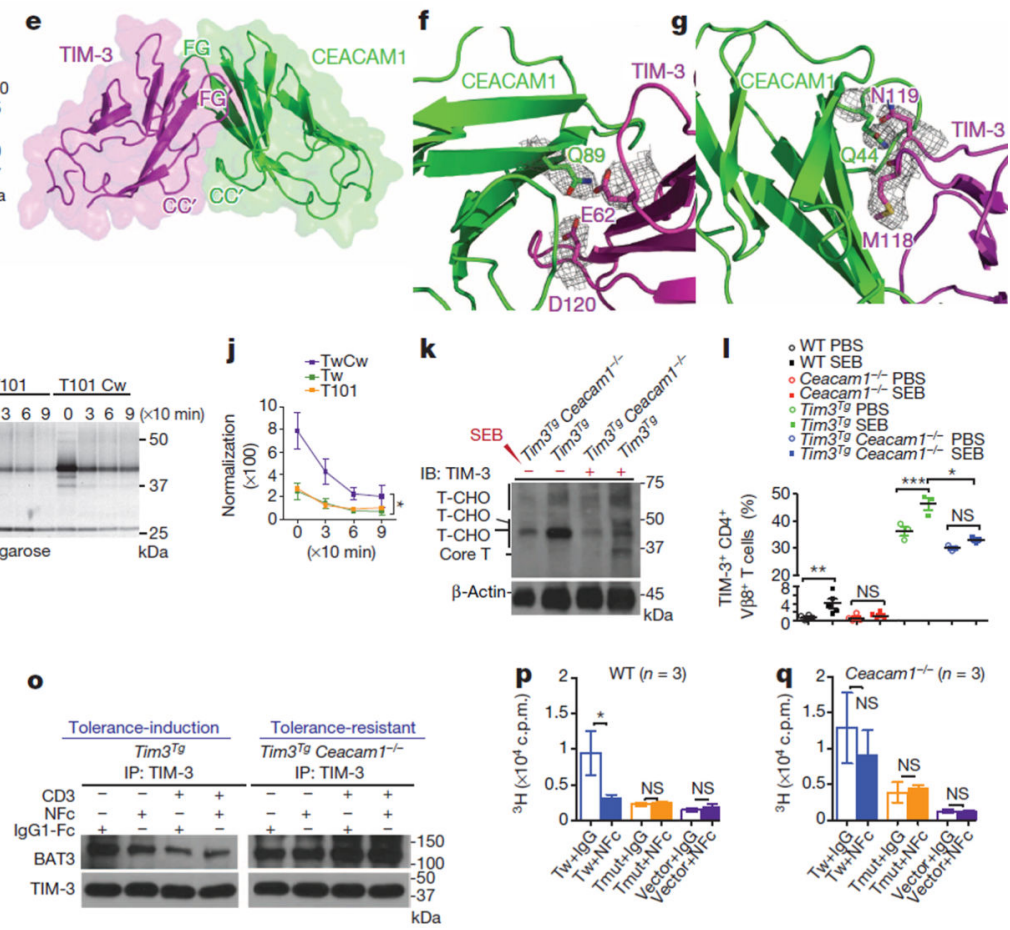

$\mathbf{k}$

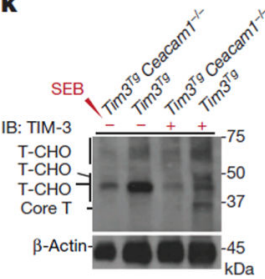

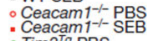

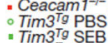
- TIm3 $3^{T g}$ Ceacaaram 1- PBS
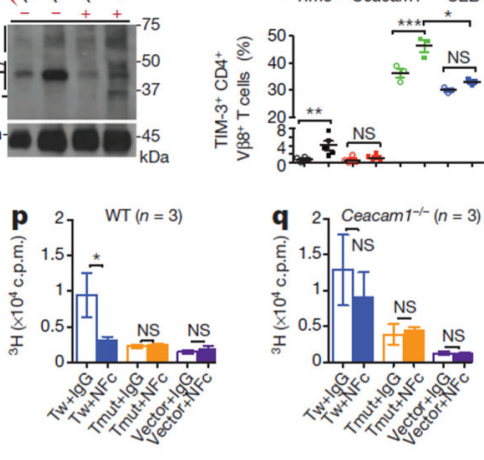

Figure 2. CEACAM1 and TIM-3 heterodimerize and serve as heterophilic ligands a, b, Co-immunoprecipitation (IP) and immunoblot (IB) of wild-type hCEACAM1 and hTIM-3 in co-transfected HEK293T cells, c, d, Co-immunoprecipitation and immunoblot of wild-type hCEACAM1 and hTIM-3 mutants (c) or wild-type hTIM-3 and hCEACAM1 mutants (d) as in a and b. e, Human CEACAM1 (IgV)-TIM-3 (IgV) heterodimer structure, $\mathbf{f}, \mathbf{g}, 2 F_{o}-F_{c}$ maps contoured at $0.9 \sigma$ showing electron densities, $\mathbf{h}, \mathbf{i}$, Autoradiogram of anti-haemagglutinin (HA) (hTIM-3) immunoprecipitate from metabolic-labelled (h) and pulse-chase metabolic-labelled (i) co-transfected HEK293T cells. CHO, carbohydrate; core T, non-glycosylated hTIM-3; Cw, wild-type hCEACAM1; EndoH, endoglycosidaseH; H2MA, HA-tagged influenza virus A M2 protein; T, hTIM-3 (Thr101Ile); Tw, wild-type hTIM-3. hTIM-3 isoforms noted. j, Quantification of densities in $\mathbf{i}$ ( $n=3$ per group). $\mathbf{k}$, Immunoblot for mTIM-3 from PBS-treated (-) or SEB-treated (+) $\mathrm{CD}^{+}{ }^{+} \mathrm{T}$ cells. Labelling as in $\mathbf{h}$ and i. 1, mTIM-3 expression after SEB tolerance induction, $\mathbf{m}$, Column-bound glutathione $S$-transferase (GST)-hTIM-3 IgV-domain pull-down of hCEACAM1 detected by immunoblot. GST ${ }^{2}$, GST-hTIM-3 dimer. Ft, flow through, n, Suppression of mouse CD4+ T-cell proliferation by mCEACAM1 N-terminal domain-Fc fusion protein (NFc). o, Immunoprecipitation of mTIM-3 and immunoblot for BAT3 or mTIM-3 from lysates of $\mathrm{CD}^{+} \mathrm{T}$ cells. $\mathbf{p}, \mathbf{q}$, Proliferation of $\mathrm{CD}^{+}{ }^{+} \mathrm{T}$ cells from wild-type $(\mathbf{p})$ and $\mathrm{CeaCAM1}^{-/-}(\mathbf{q})$ mice transduced with wild-type mTIM-3 (Tw), mTIM-3 $3^{\Delta 252-281}$ (Tmut) or vector exposed to anti-CD3 and either NFc or IgG1-Fc (IgG1). Data are mean \pm s.e.m. and represent five (a, b), four $(\mathbf{c}, \mathbf{d})$, three $(\mathbf{h}-\mathbf{j}, \mathbf{l}, \mathbf{n}, \mathbf{p}, \mathbf{q})$ and two $(\mathbf{k}, \mathbf{m}, \mathbf{o})$ independent experiments. NS, not significant; $* P<0.05 ; * * P<0.01 ; * * * P<0.001$. 
a
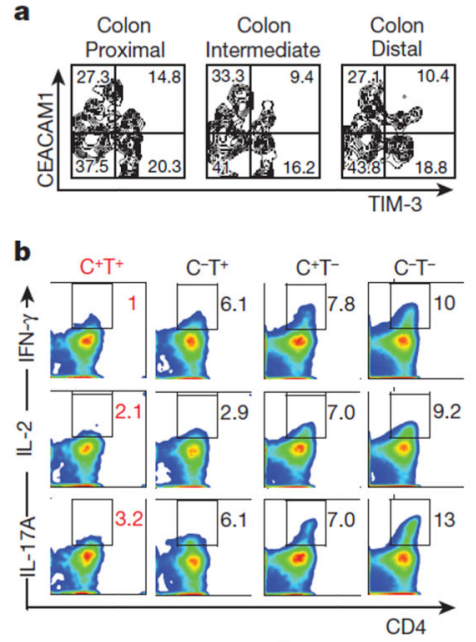

C
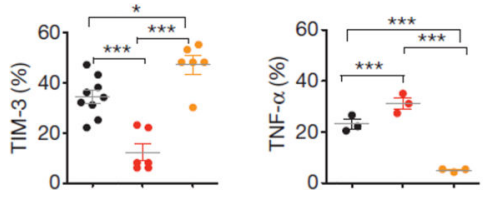

e - WT $(n=8)$ - Ceacam1-4L ${ }^{\top g}$ Ceacam $^{-1-}(n=5)$

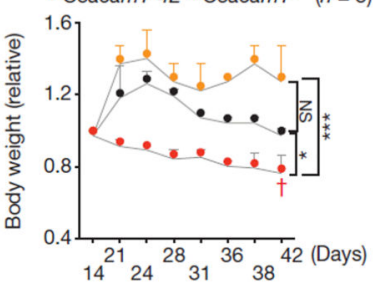

h

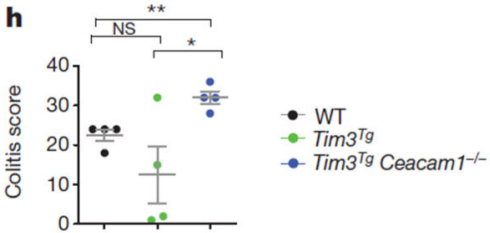

f $\bullet W T$

- Ceacam1-1-

- Ceacam1-4L $L^{T g}$ Ceacam1 1-

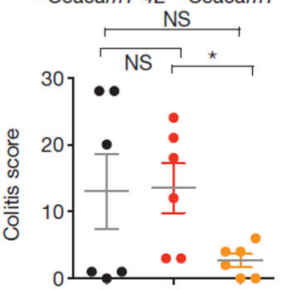

i g $\quad-W T(n=8)$

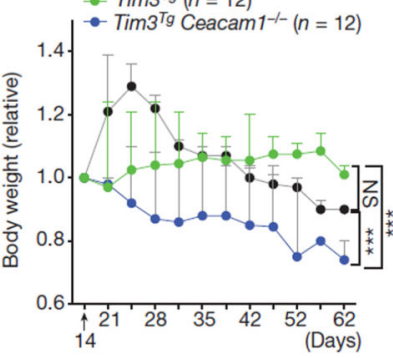

RNA expression

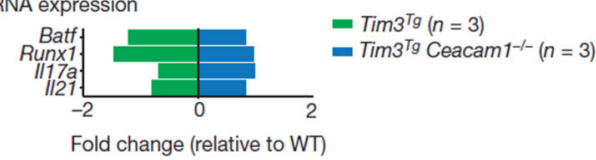

j
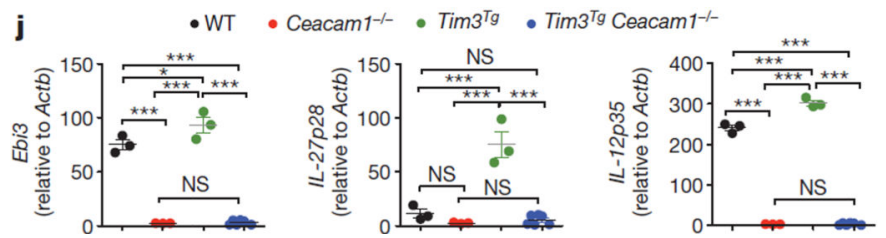

- WT - Ceacam1-4L ${ }^{T g}$ Ceacam1-1- $^{-1}$

Figure 3. TIM-3 regulation of mucosa-associated inflammation requires CEACAM1 a, mCEACAM1 and mTIM-3 expression on colonic lamina propria CD4 ${ }^{+} \mathrm{T}$ cells, $\mathbf{b}$, Intracellular cytokines in cells described in a. c, d, mTIM-3 (c) and intracellular TNF-a (d) expression in lamina propria $\mathrm{CD} 4^{+} \mathrm{T}$ cells from indicated donors, $\mathbf{e}$, Body weights relative to weights on day 14 of groups in $\mathbf{c}$ and $\mathbf{d}$. Five mice expired $(\dagger)$. f, Score of surviving mice of groups in e. g, Body weights of genotypes as in e. h, Score of groups described in $\mathbf{g} . \mathbf{i}, \mathbf{j}$, Nanostring (i) and quantitative PCR (j) of lamina propria mononuclear cells. Actb, $\beta$-actin gene. All data are mean \pm s.e.m. and represent six $(\mathbf{a})$, four $(\mathbf{b})$ and three $(\mathbf{c}-\mathbf{j})$ independent experiments. $* P<0.05 ; * * P<0.01 ; * * * P<0.001$. 


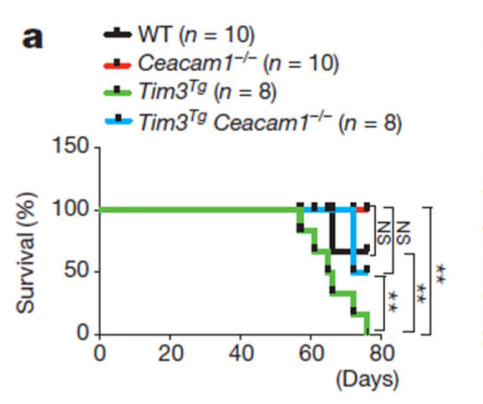

e Tumour-infiltrating

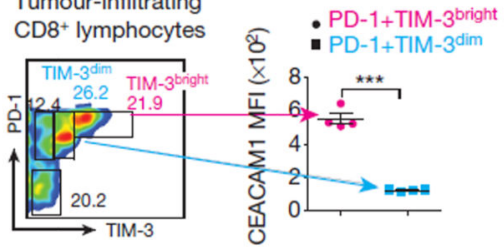

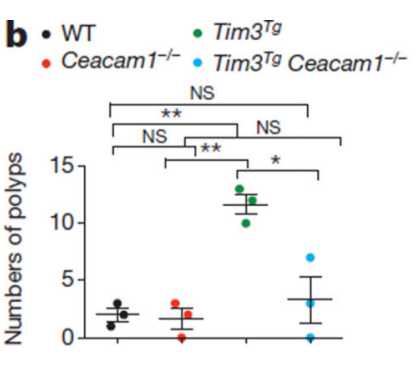

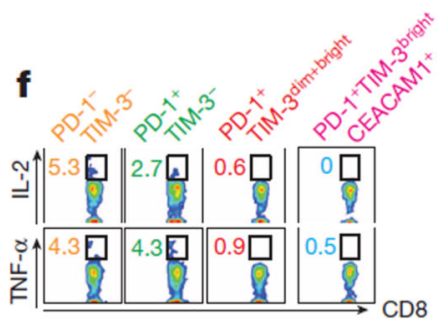

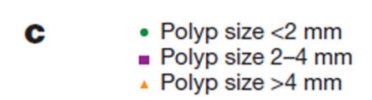

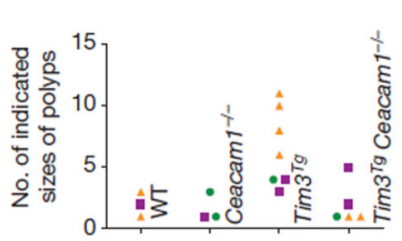

d $\quad$ Adenoma

- High-grade dysplasia

$\triangle$ Adenocarcinoma

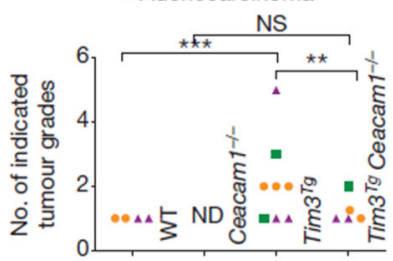

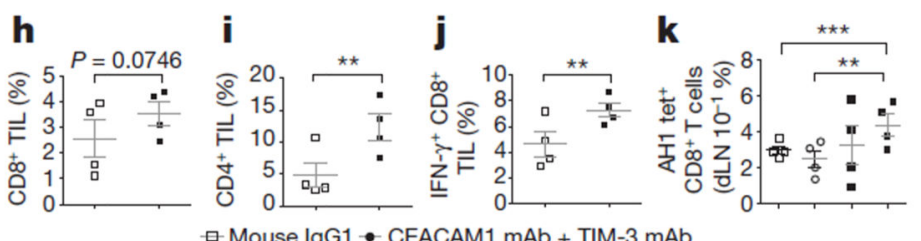
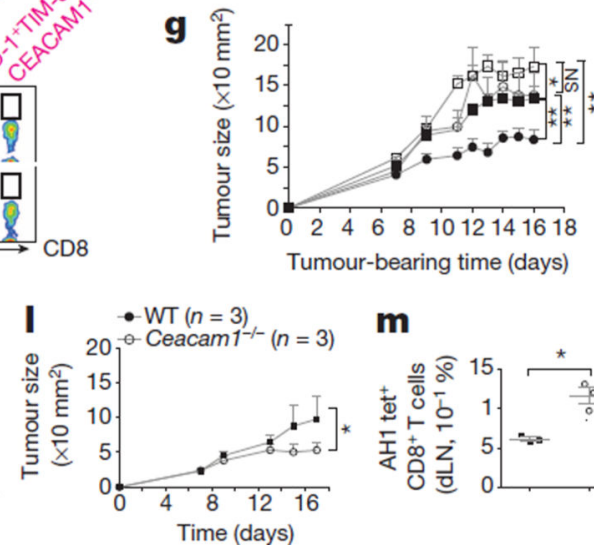

$\square$ Mouse lgG1

- TIM-3 mAb

- CEACAM1 mab

- CEACAM1 mAb + TIM-3 mAb

๑ Mouse IgG1 - CEACAM1 mAb + TIM-3 mAb
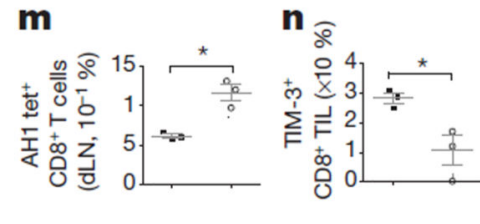

Figure 4. CEACAM1 determines TIM-3 regulation of anti-tumour immune responses

a, Survival curves in AOM/2.5\% DSS model. b-d, Assessment of polyp numbers (b), polyp size (c) and cancer grades (d) in AOM/1.5\% DSS model, e, Staining of $\mathrm{CD}^{+} \mathrm{T}$ cells associated with CT26 tumours. f, Intracellular cytokine expression in TIL subsets after antiCD3 stimulation. g, Prevention of CT26 tumour growth in wild-type mice ( $n=5$ per group). $\mathrm{mAb}$, monoclonal antibody. $\mathbf{h}-\mathbf{k}$, Analysis of TILs for relative proportion of $\mathrm{CD}^{+}(\mathbf{h})$ and $\mathrm{CD}^{+}(\mathbf{i}) \mathrm{T}$ cells, IFN- $\gamma^{+} \mathrm{CD}^{+} \mathrm{T}$ cells $(\mathbf{j})$ and tumour-specific (AH1-tetramer, tet ${ }^{+}$) $\mathrm{CD}^{+} \mathrm{T}$ cells in draining lymph nodes (dLN) (k) in groups described in g. l-n, Growth of CT26 cells (1), AH1 tet ${ }^{+} \mathrm{CD}^{+}{ }^{+}$cells in $\mathrm{dLN}(\mathbf{m})$ and TIM-3 expression on TILs (n) in wild-type and CeaCAM1 ${ }^{-/-}$mice. Data are mean \pm s.e.m. and represent four $(\mathbf{e})$, three $(\mathbf{g}-\mathbf{k})$ and two $(\mathbf{a}-\mathbf{d}$, f, $\mathbf{l}-\mathbf{n})$ independent experiments. $* P<0.05 ; * * P<0.01$; *** $P<0.001$. 